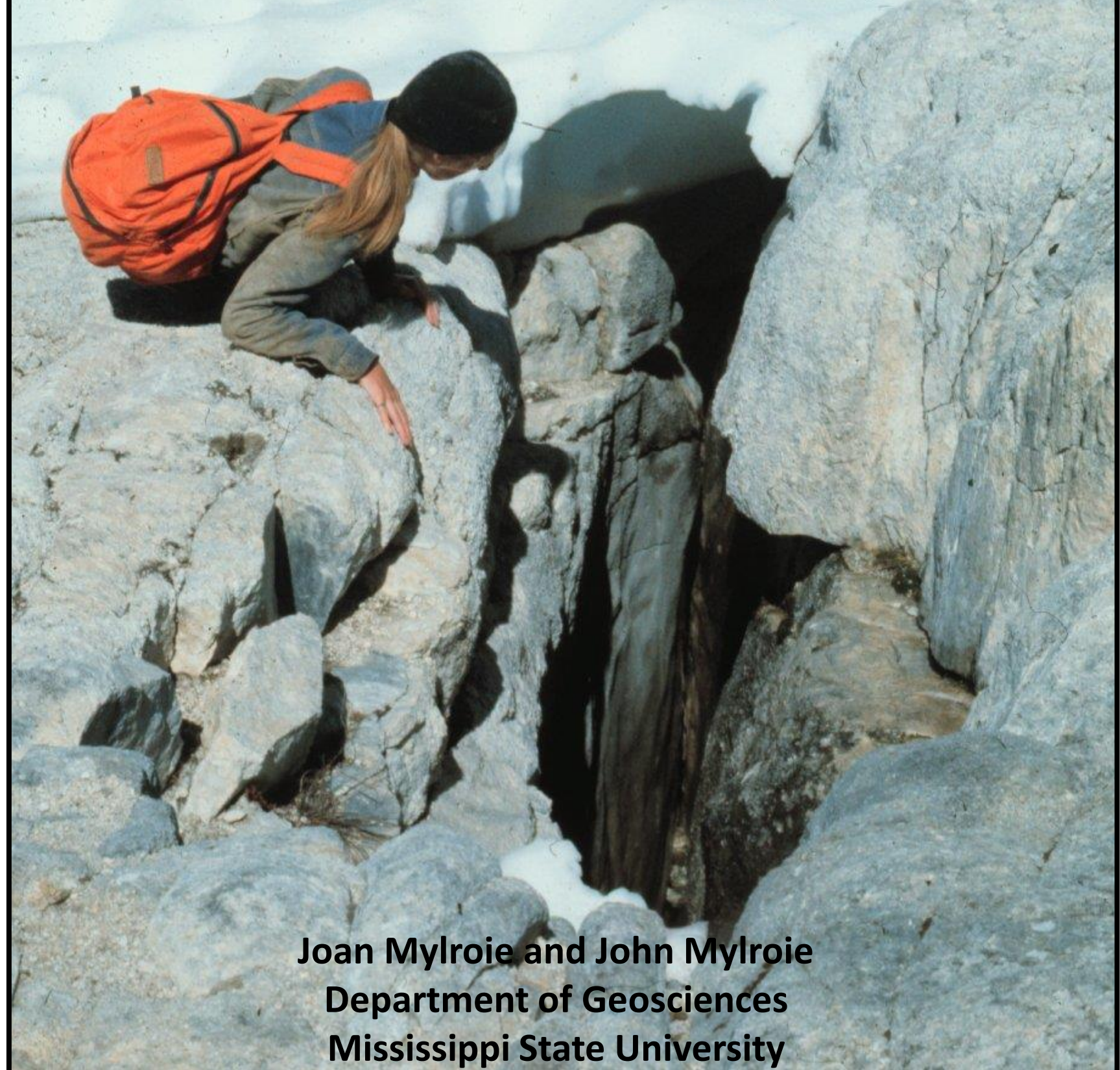




\section{Dedicated to:}

Art and Peg Palmer

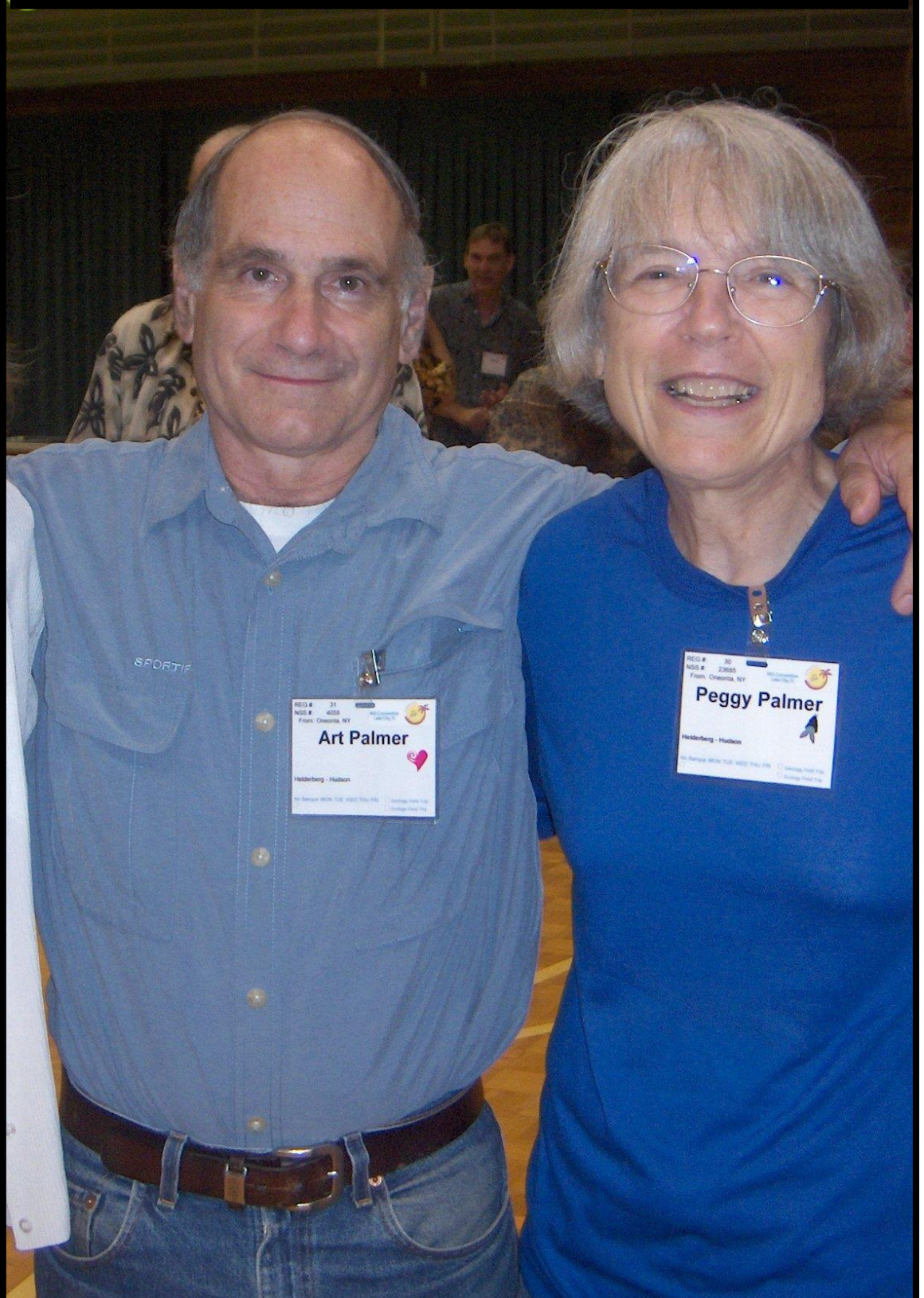


For Karst Processes, is the statement "The Present Is The Key To The Past", in the sense of Charles Lyell, David Hume and James Hutton, correct?

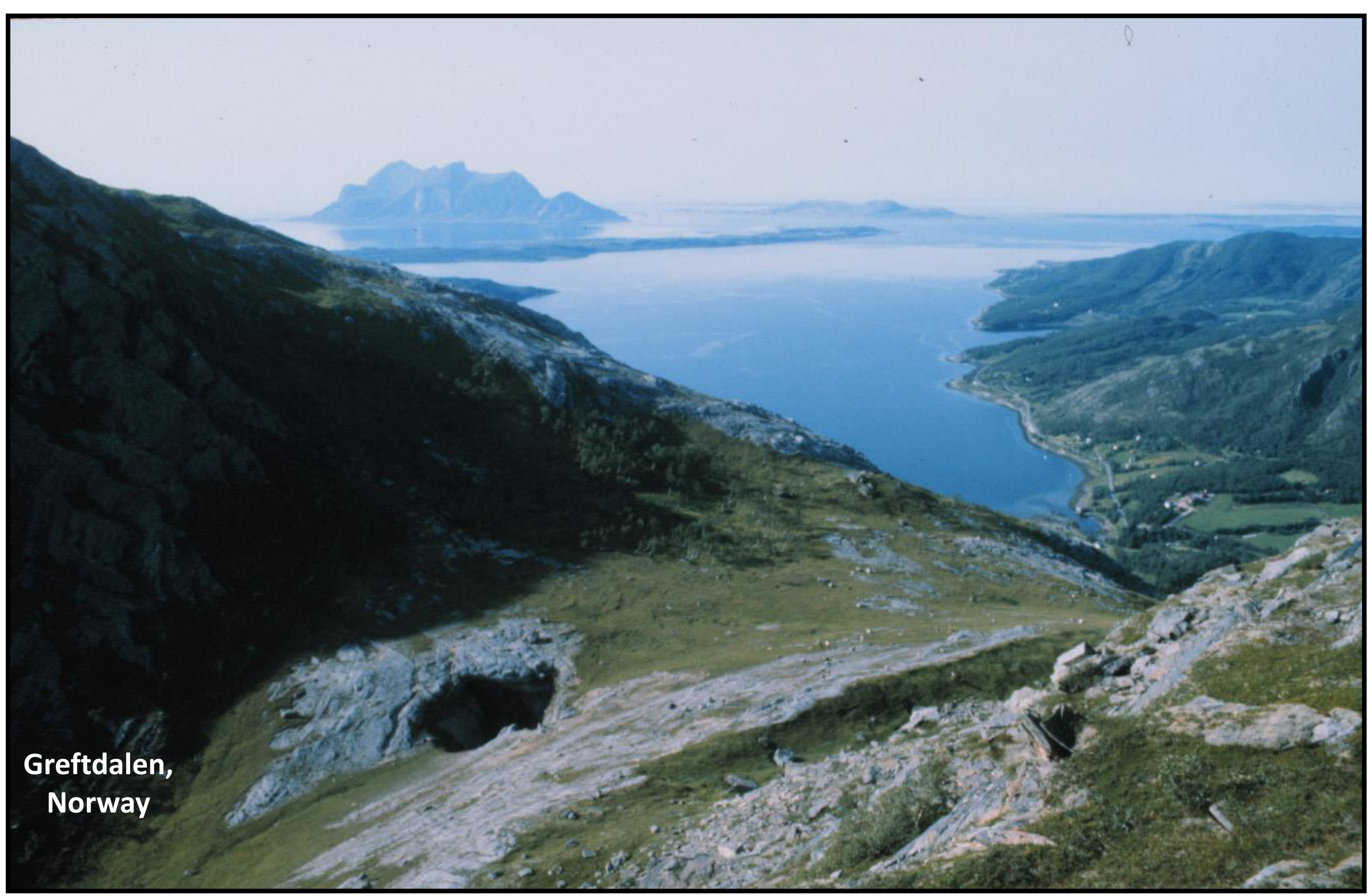


In the Phanerozoic, continental glaciations as seen in the Quaternary are rare

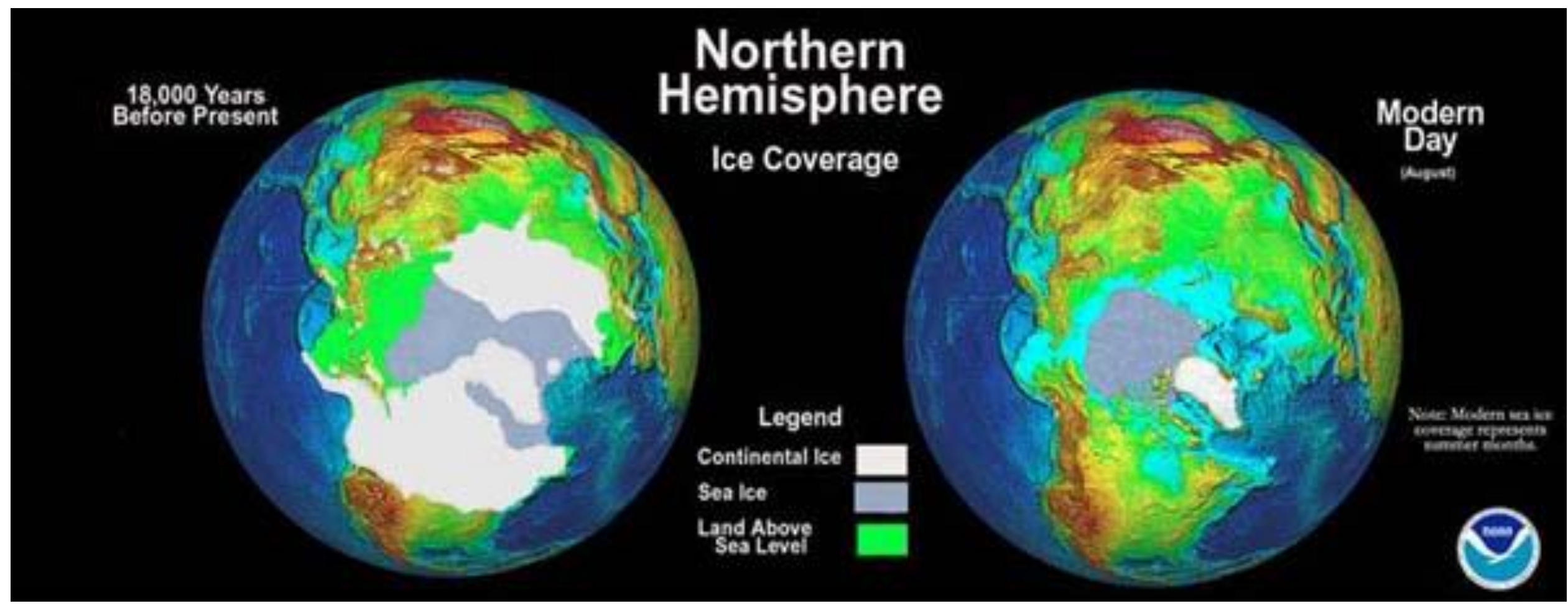




\section{Large-scale continental glaciation cannot occur}

unless the continents are in polar positions

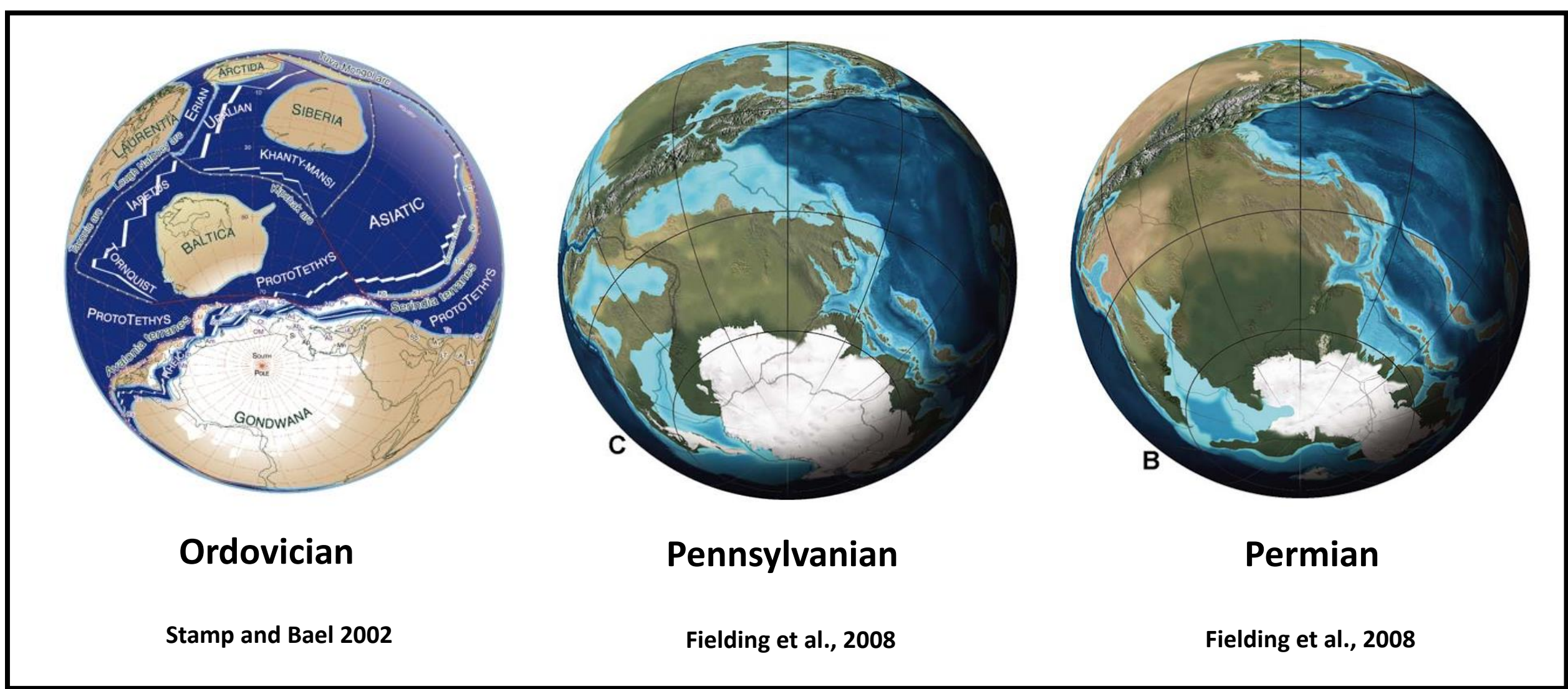




\section{How does glaciation affect Karst Processes?}

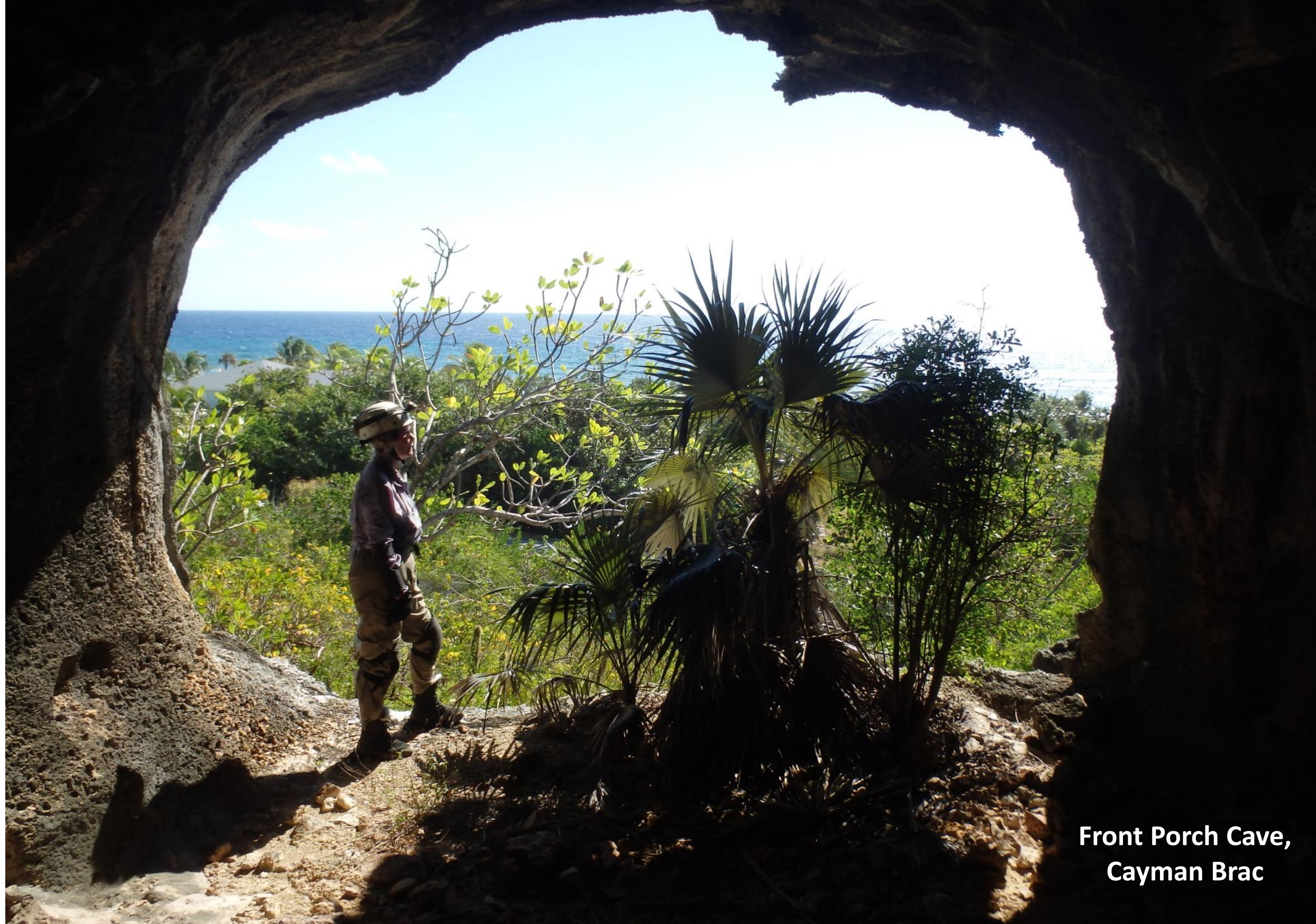




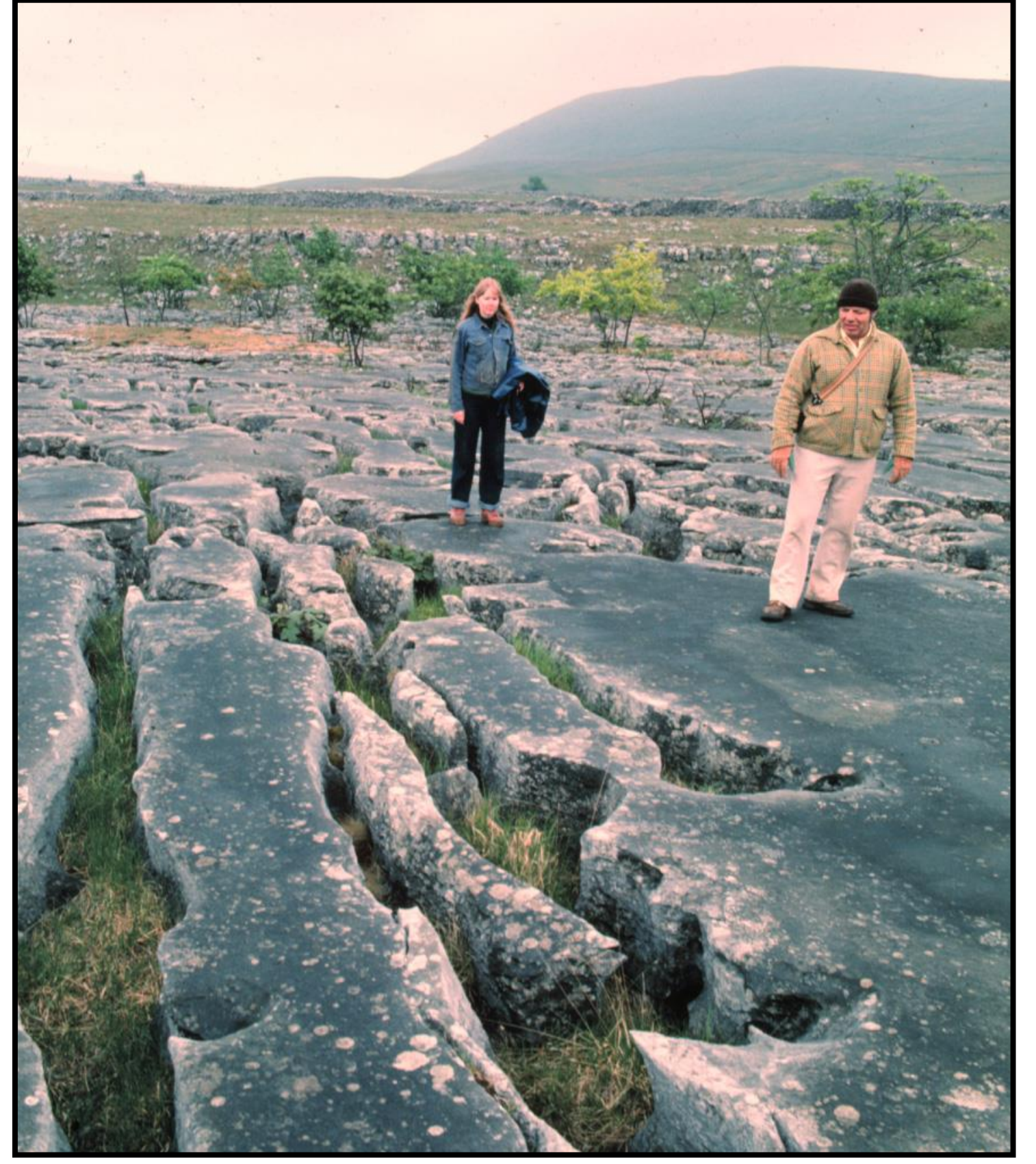

Glaciation Effects Fall Into Three Categories:

1. Ice Contact Effects

Glaciated karren, Yorkshire, UK 
Glacial ice is a hydrological as well as a mechanical influence on speleogenesis

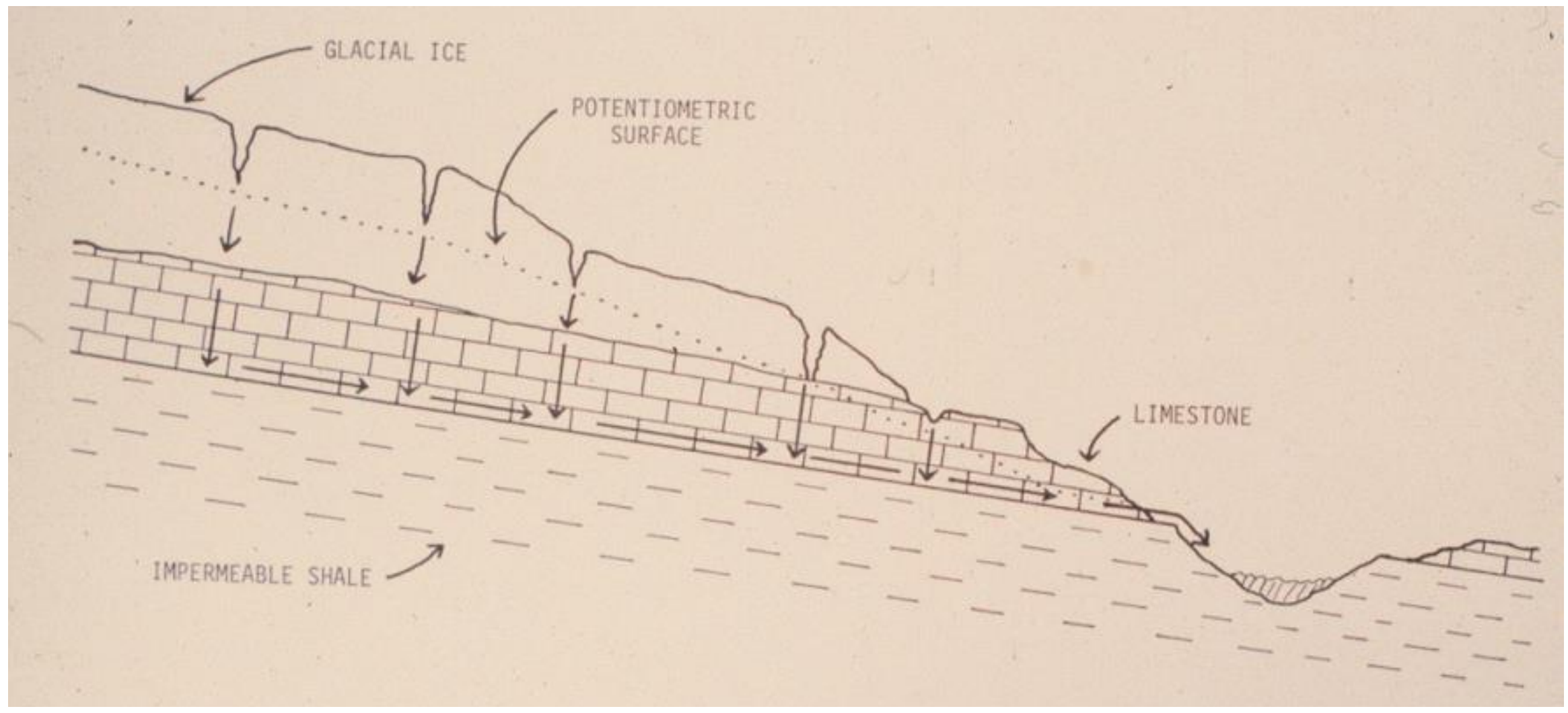

Mylroie 1984 
Flow Reversal In Glacial Valleys, Norway

When ice is in the valleys, water escapes the sole of the glacier as a phreatic lift.

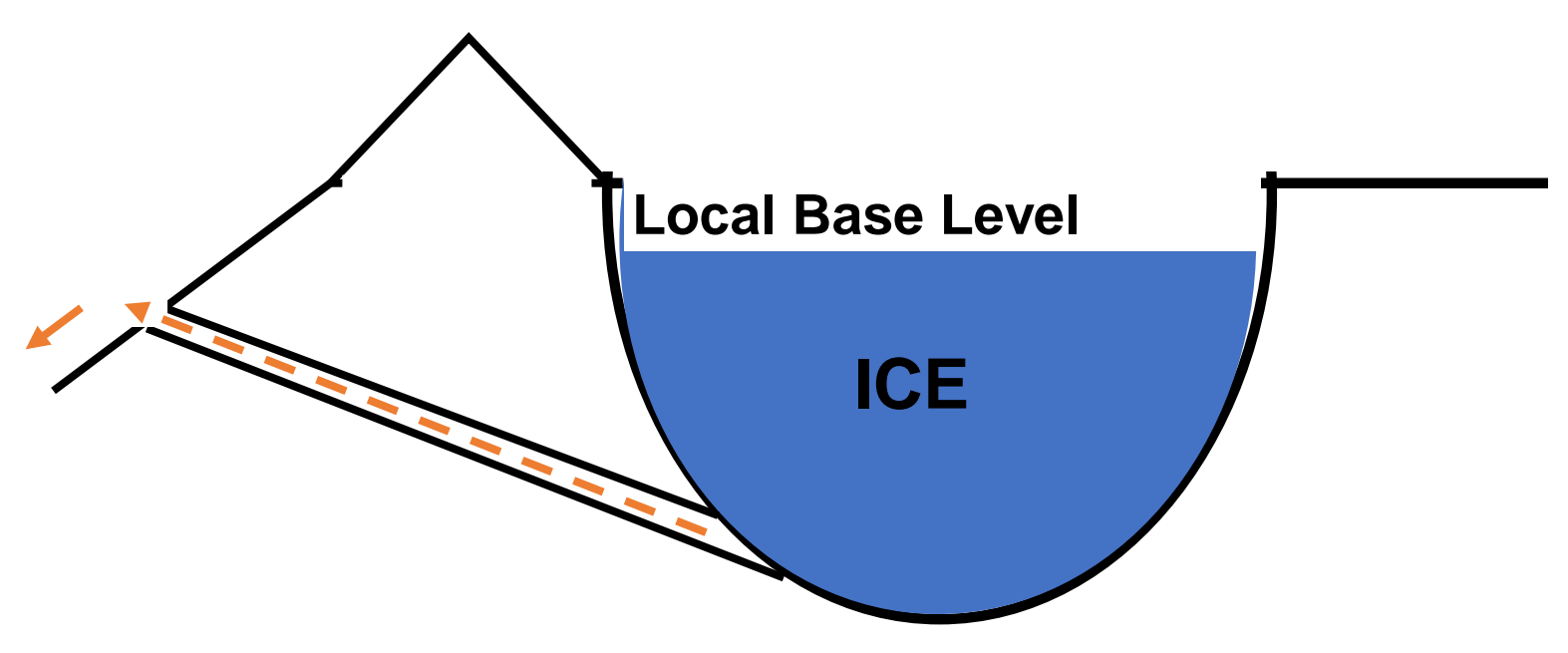

Temperate-Based Glacier 
Flow Reversal In Glacial Valleys, Norway

When ice is in the valleys, water escapes the sole of the glacier as a phreatic lift.
When the ice melts, base level drops to the valley floor, and the phreatic lift GLACIATION ENDS becomes a vadose tributary.
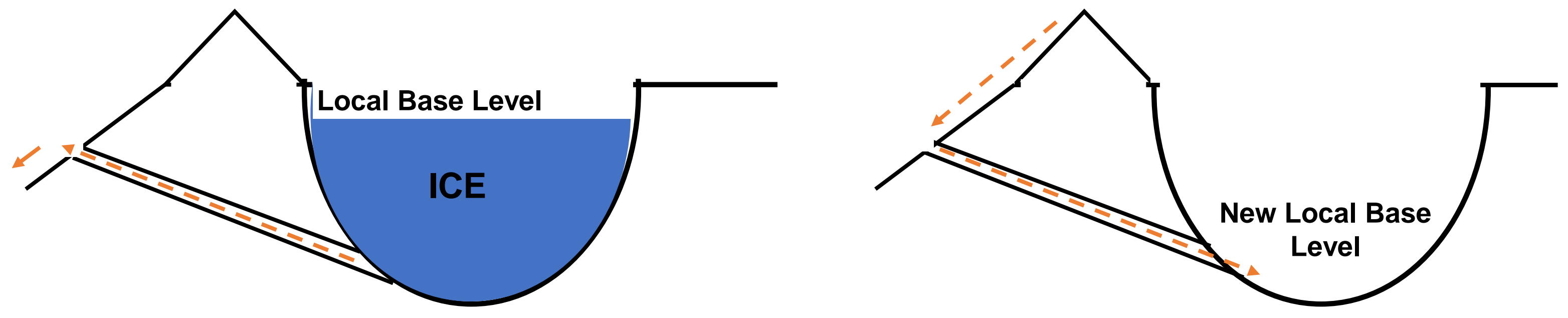

Temperate-Based Glacier 
Flow reversal, overprinting, and reactivation of cave passages are common in glaciated karst

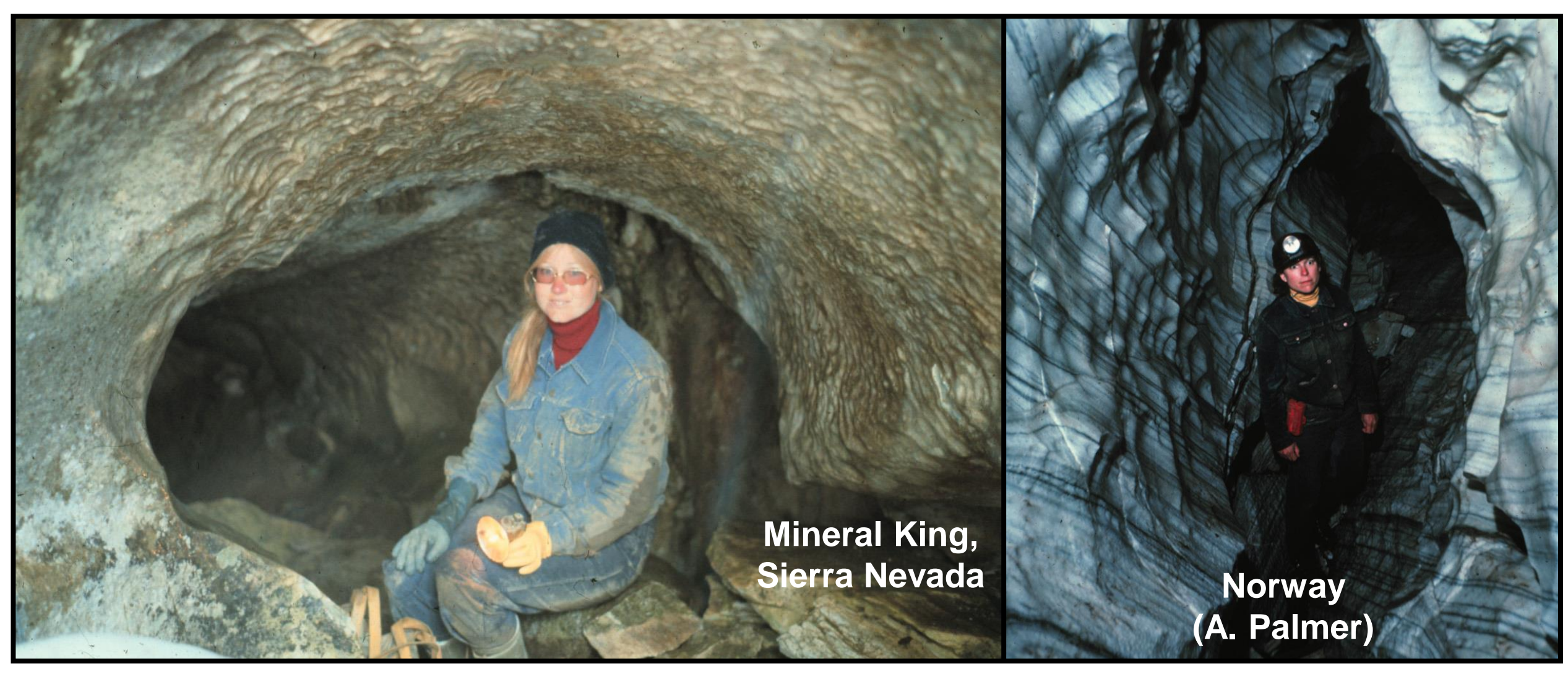


Glaciation Effects Fall Into Three Categories:

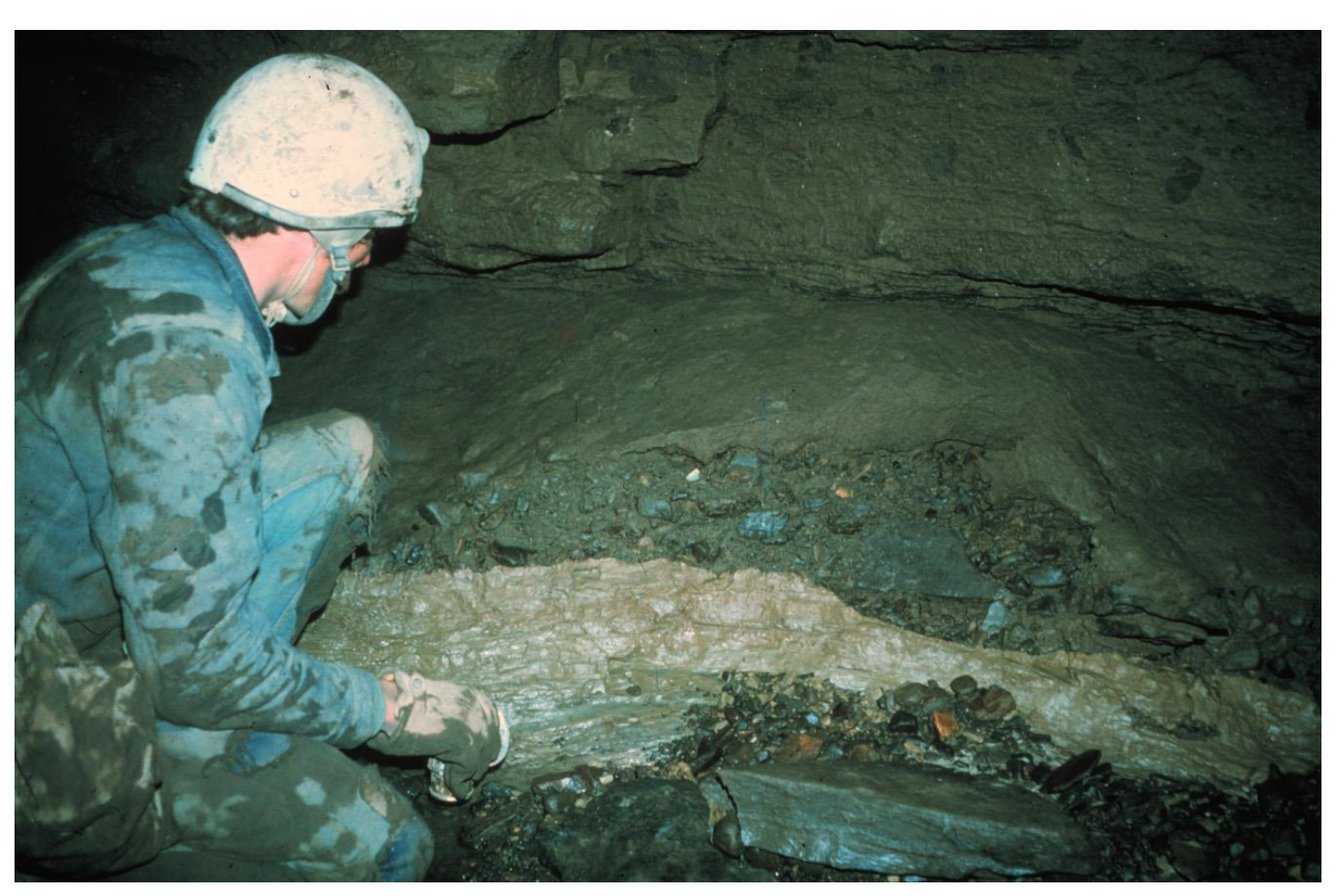
1. Ice Contact Effects
2. Ice Proximity Effects

Glacial Lake Schoharie deposits in Caboose

Cave, Schoharie County, NY 


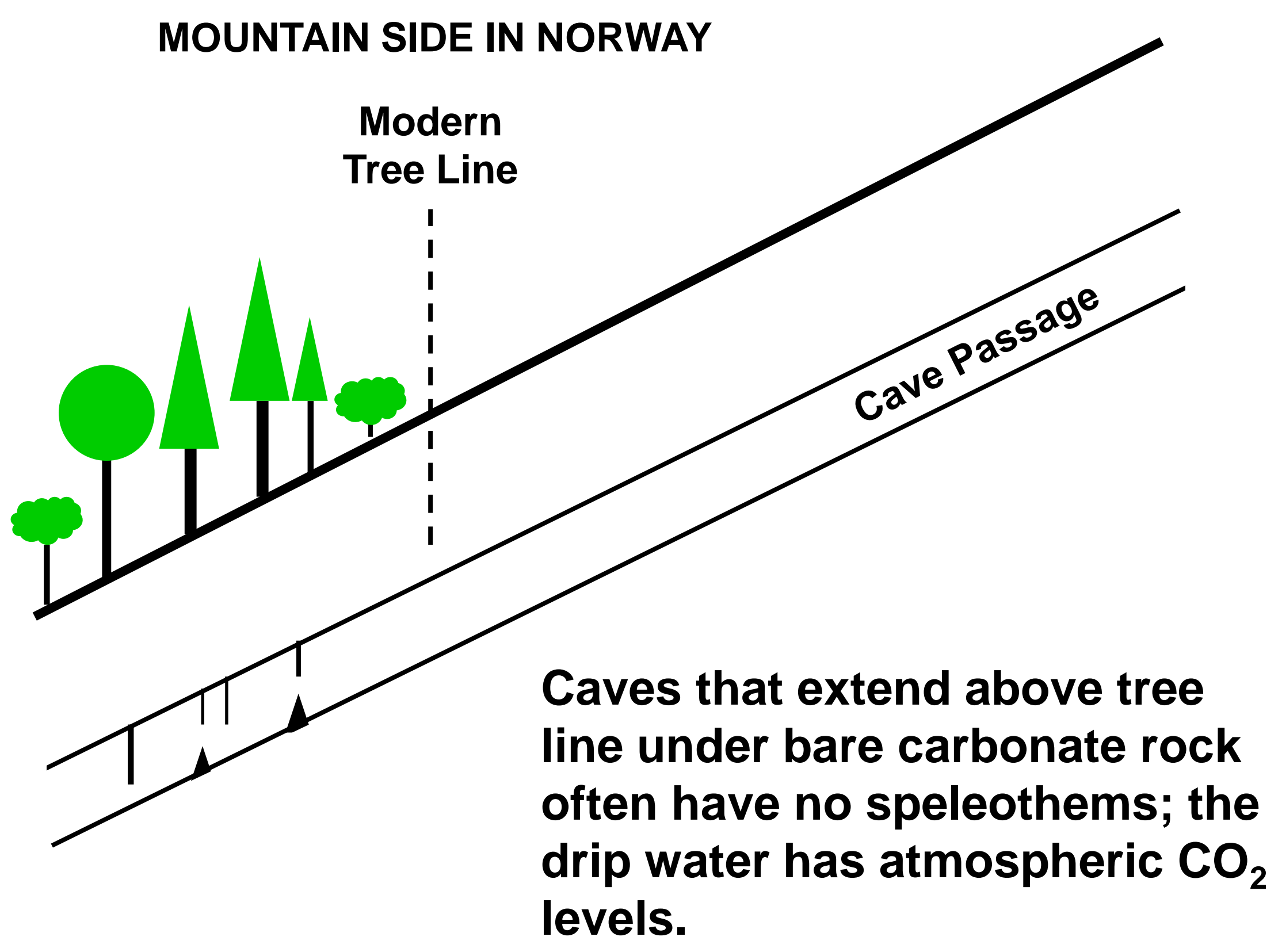




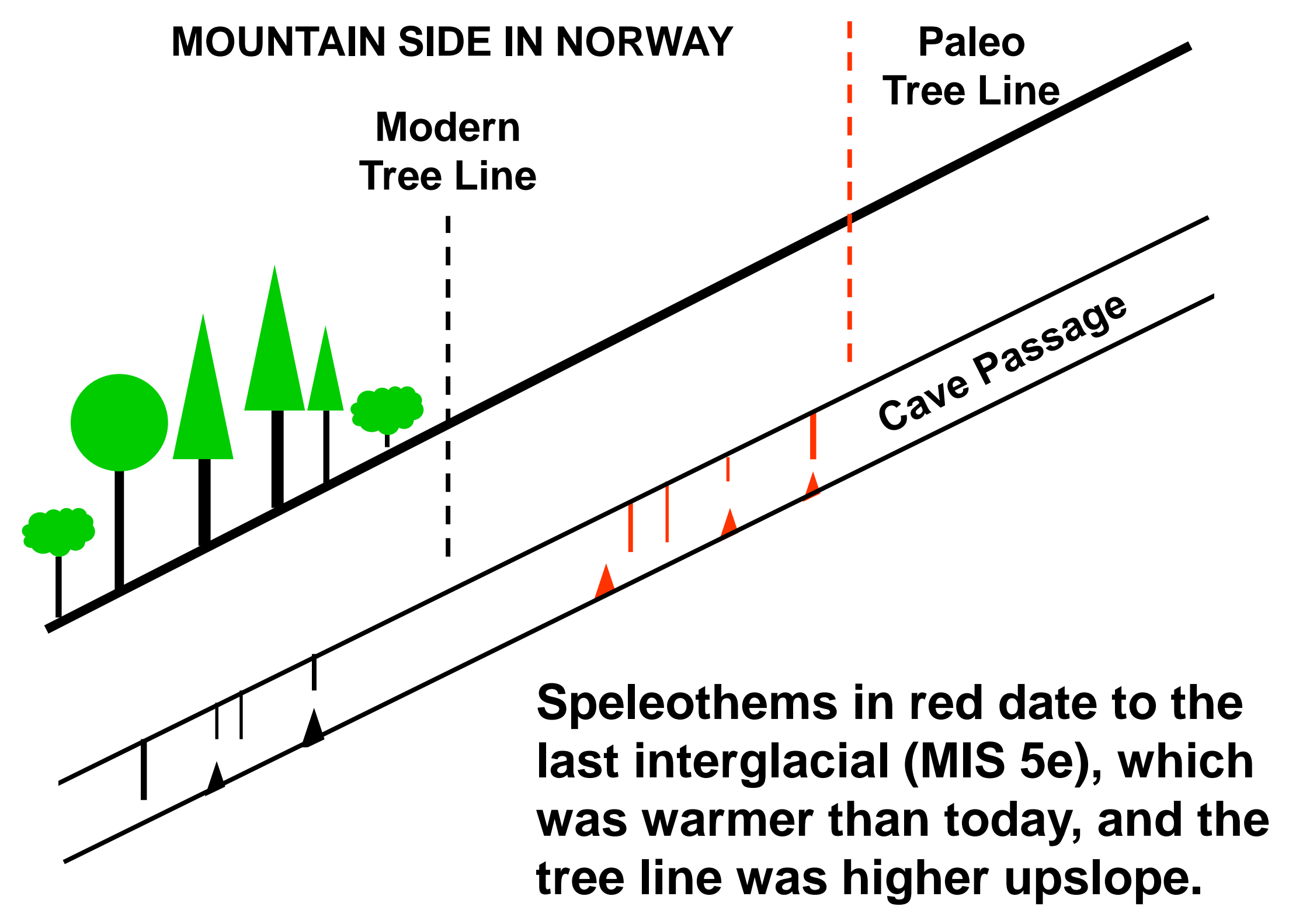




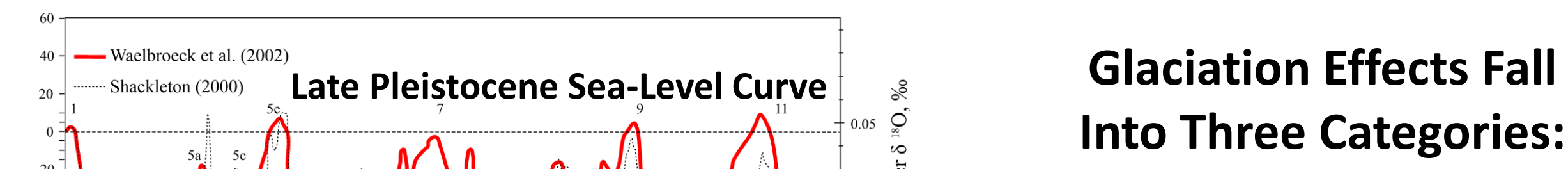

Late Pleistocene Lakes, American Southwest 


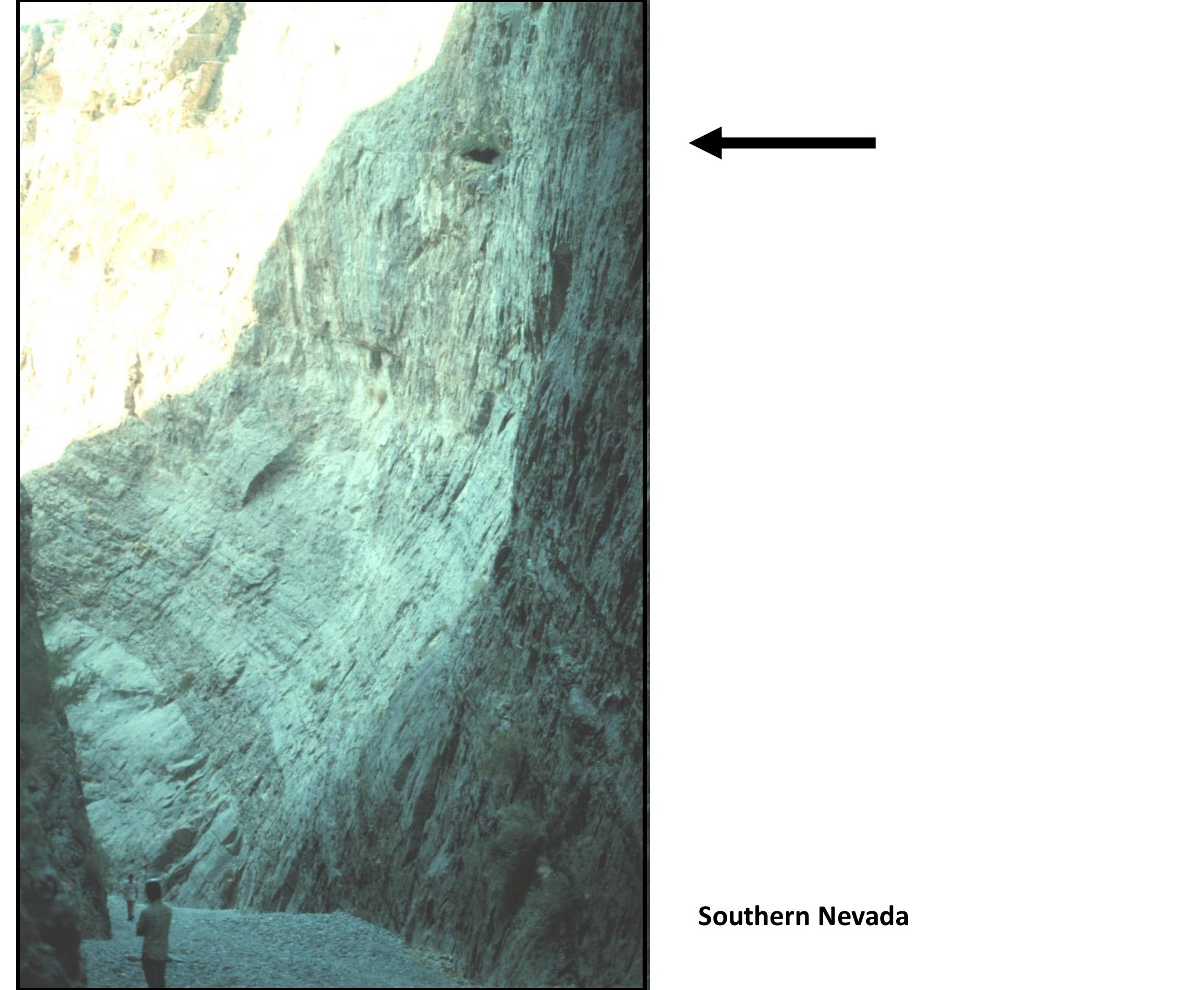




\section{We have a good grasp of how cave processes}

work today, and we extrapolate to the past

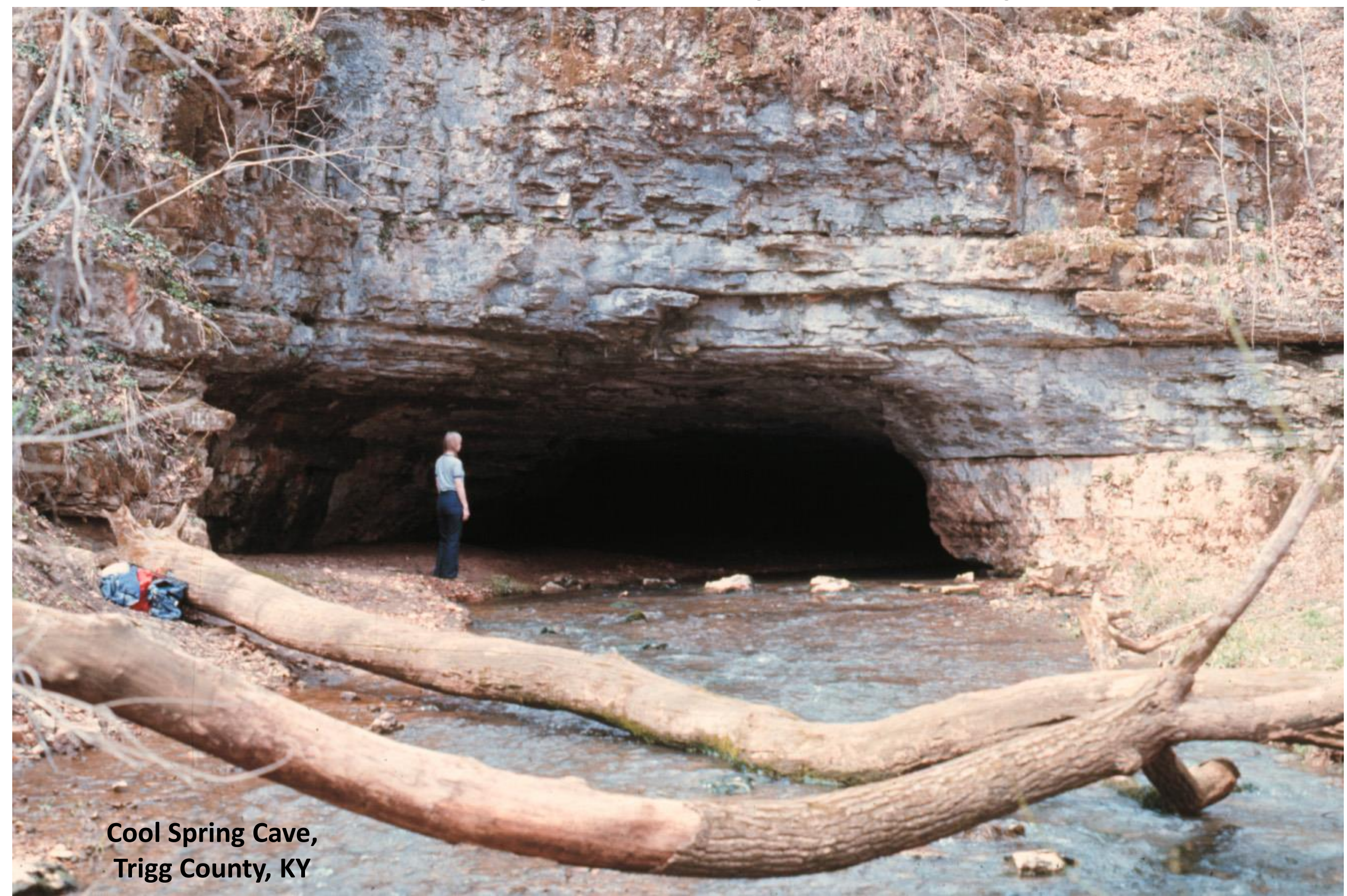


What about the Mesozoic, when there were no significant continental glaciations?

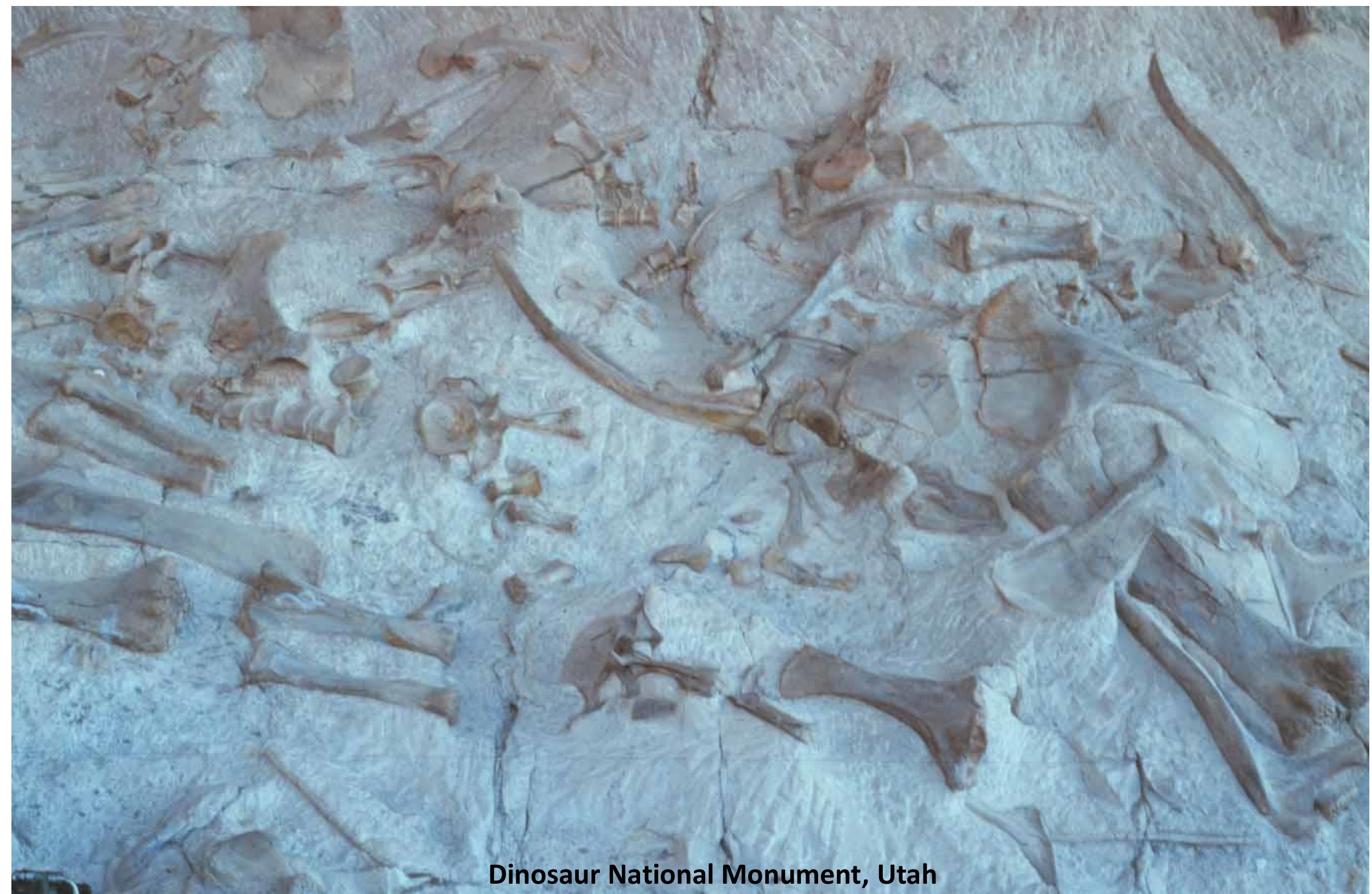


The key to resolving the question is to determine if caves are:

1. Persistent in the rock record

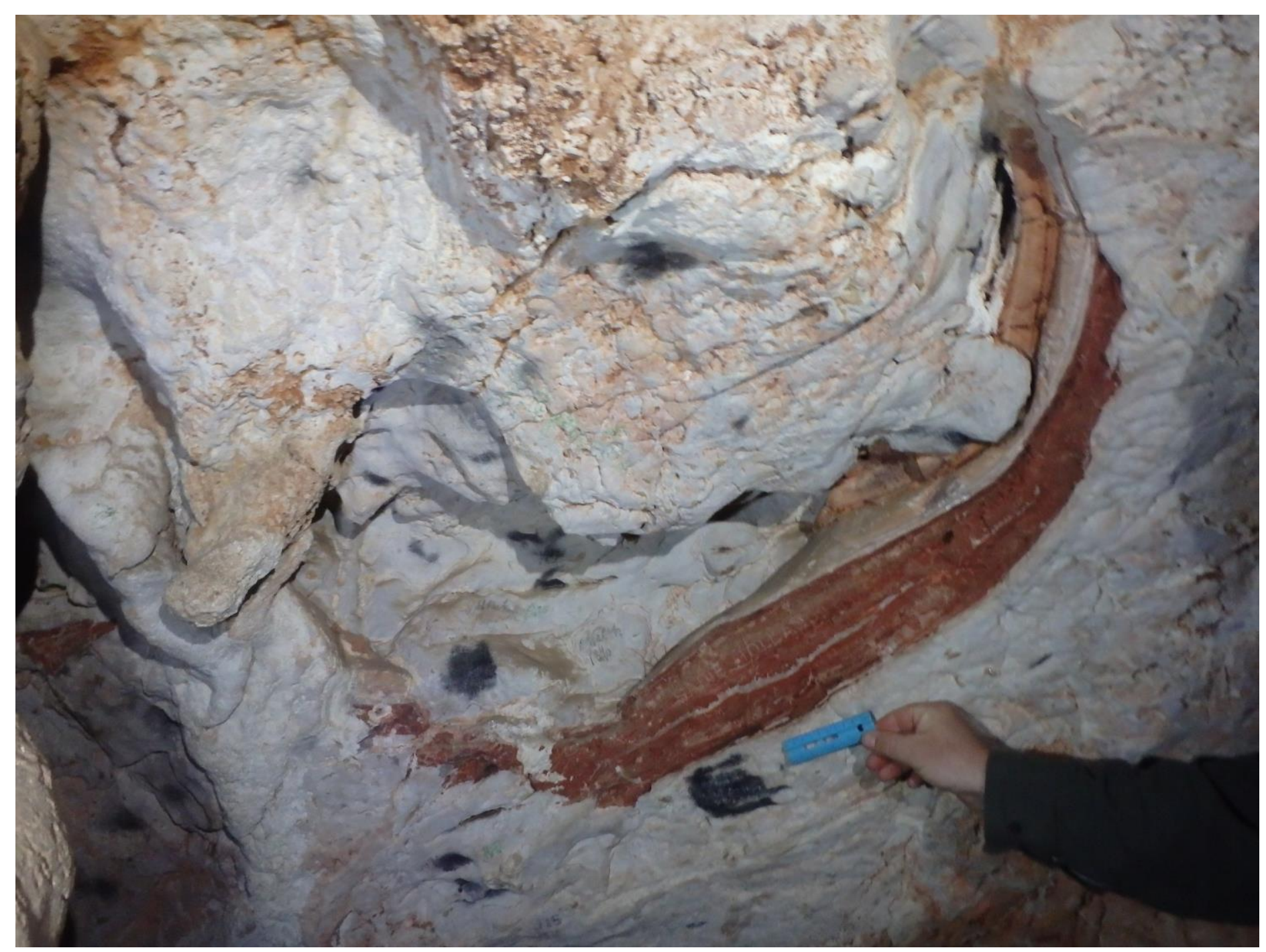

Paleozoic Cave Deposits, Jenolan, Australia 
The key to resolving the question is to determine if caves are:

1. Persistent in the rock record

2. React rapidly to changing conditions

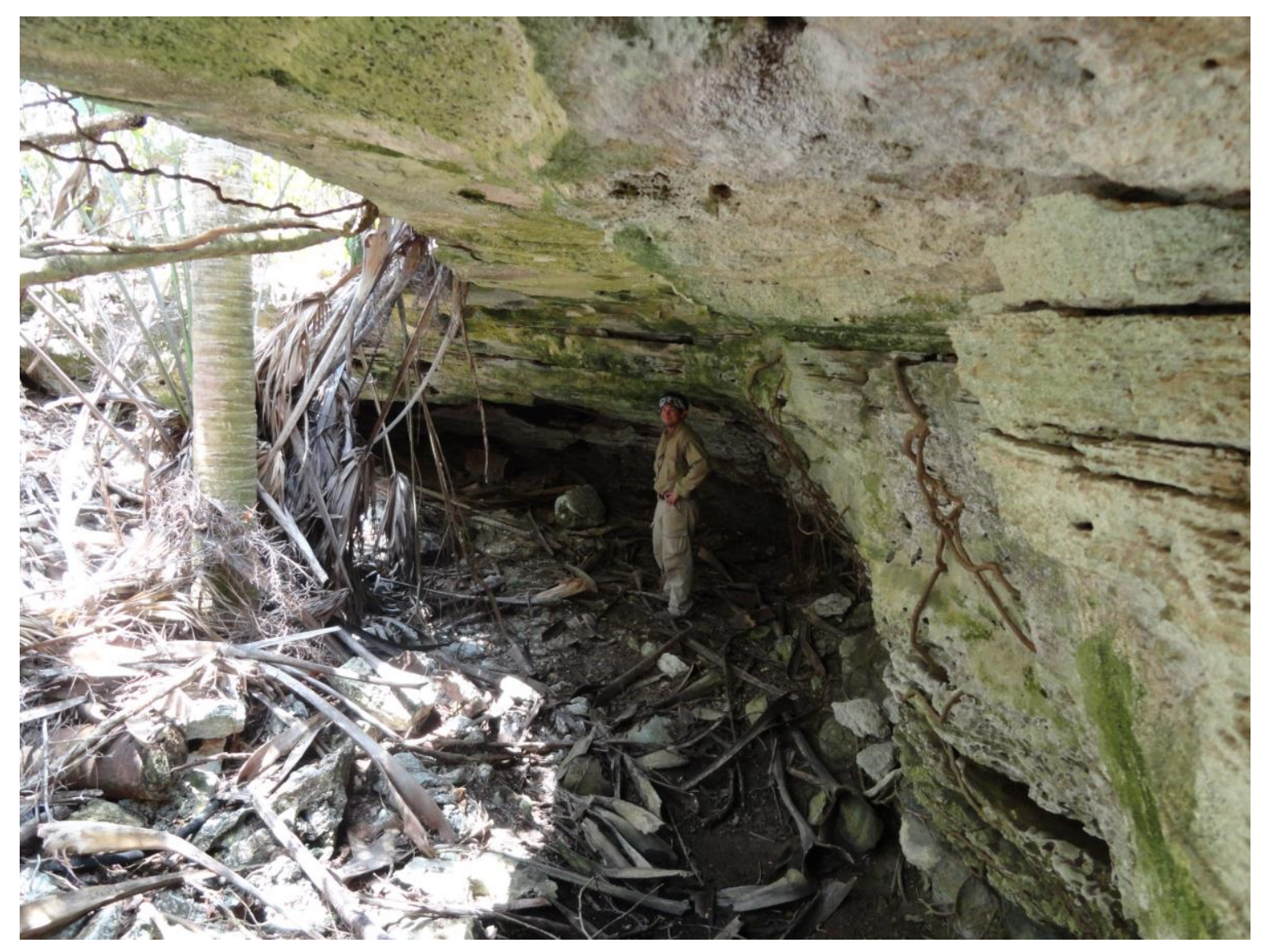

Banana Hole, San Salvador island, formed during MIS 5e 
The key to resolving the question is to determine if caves are:

1. Persistent in the rock record

2. React rapidly to changing conditions

3. Survive those changing conditions

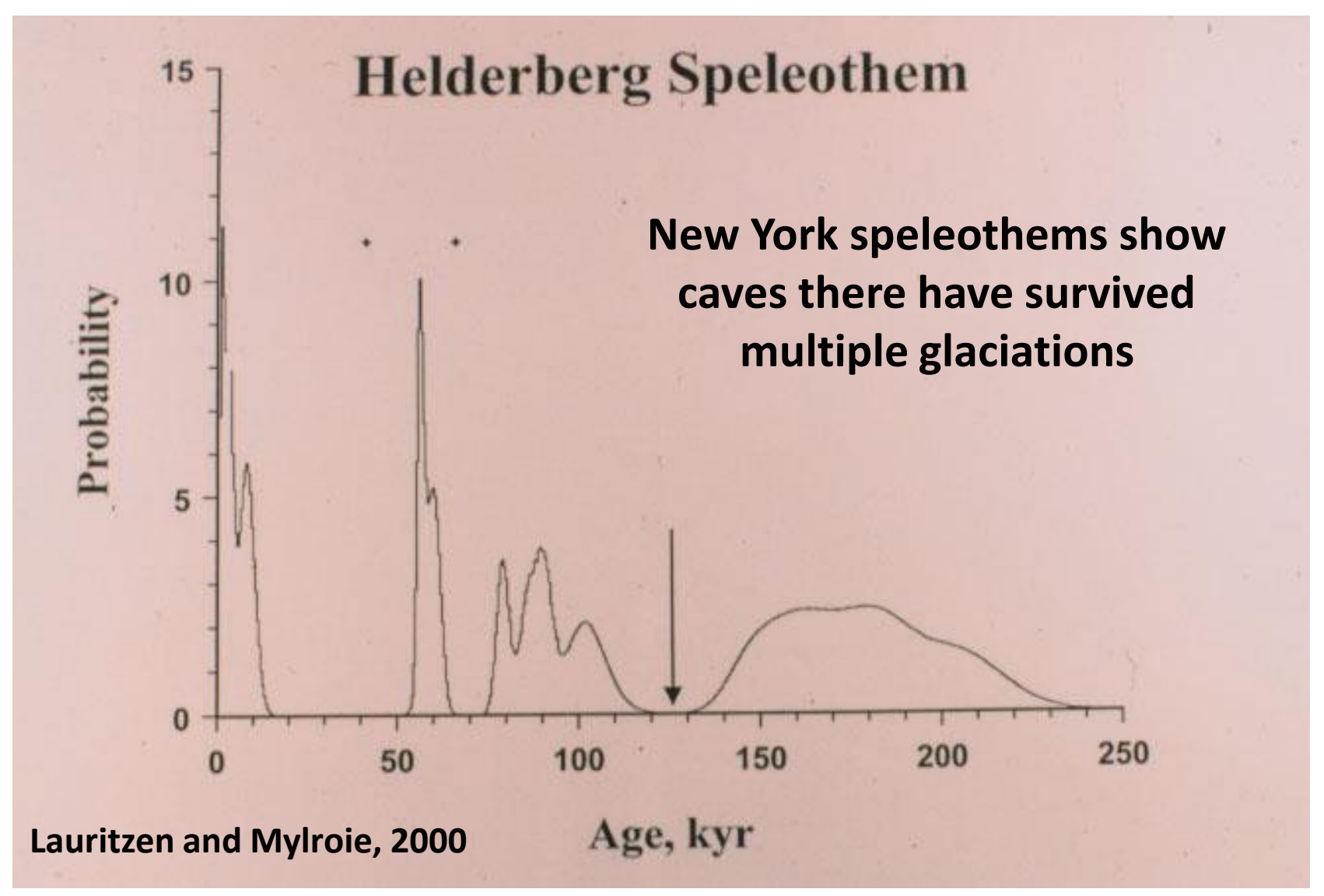


Cave passages have formed post glacially to adapt to the new and deranged surficial flow system.

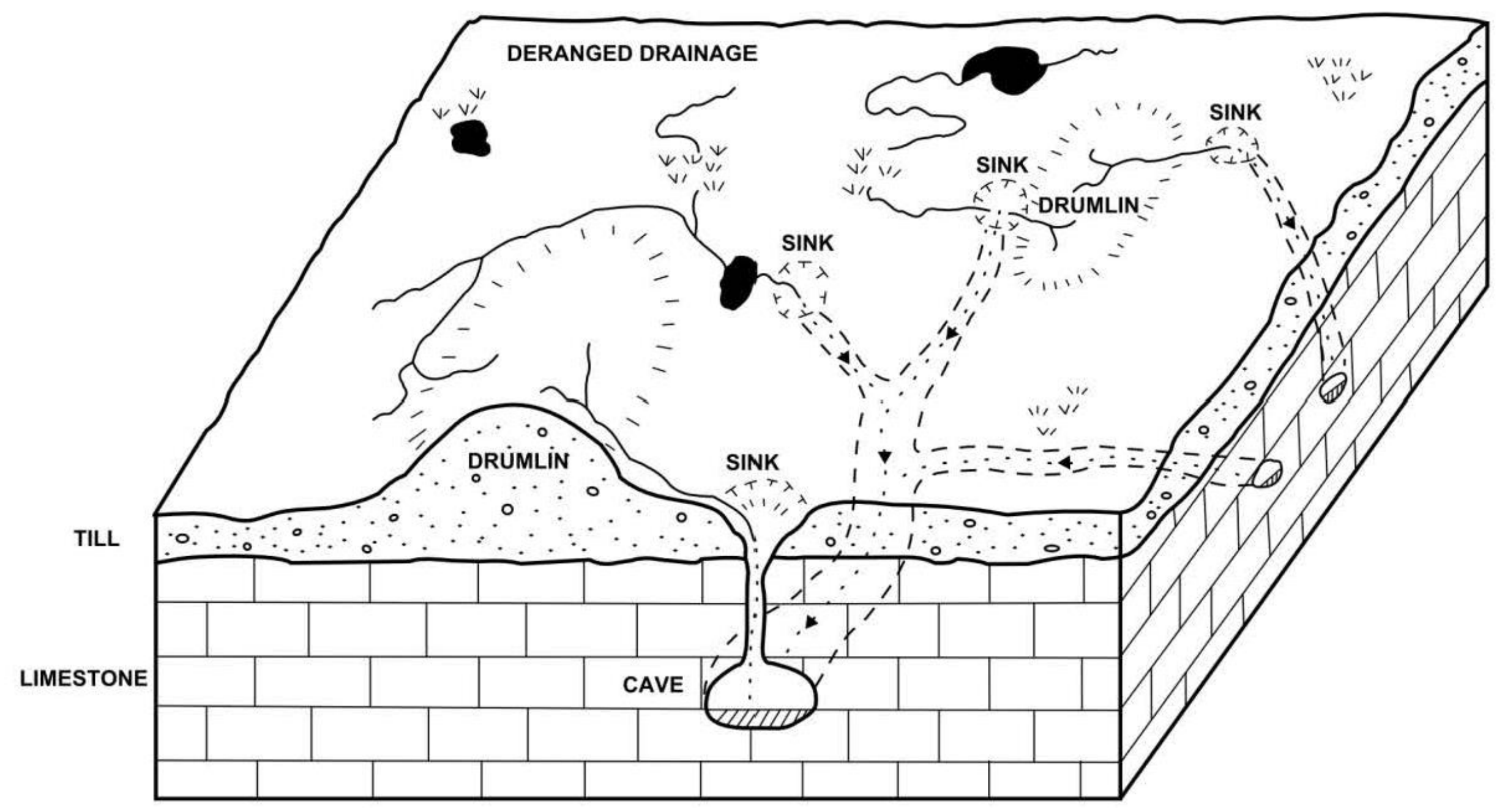

Cooper and Mylroie, 2014 
Post-glacial backflood maze caves are found along post-glacial rivers

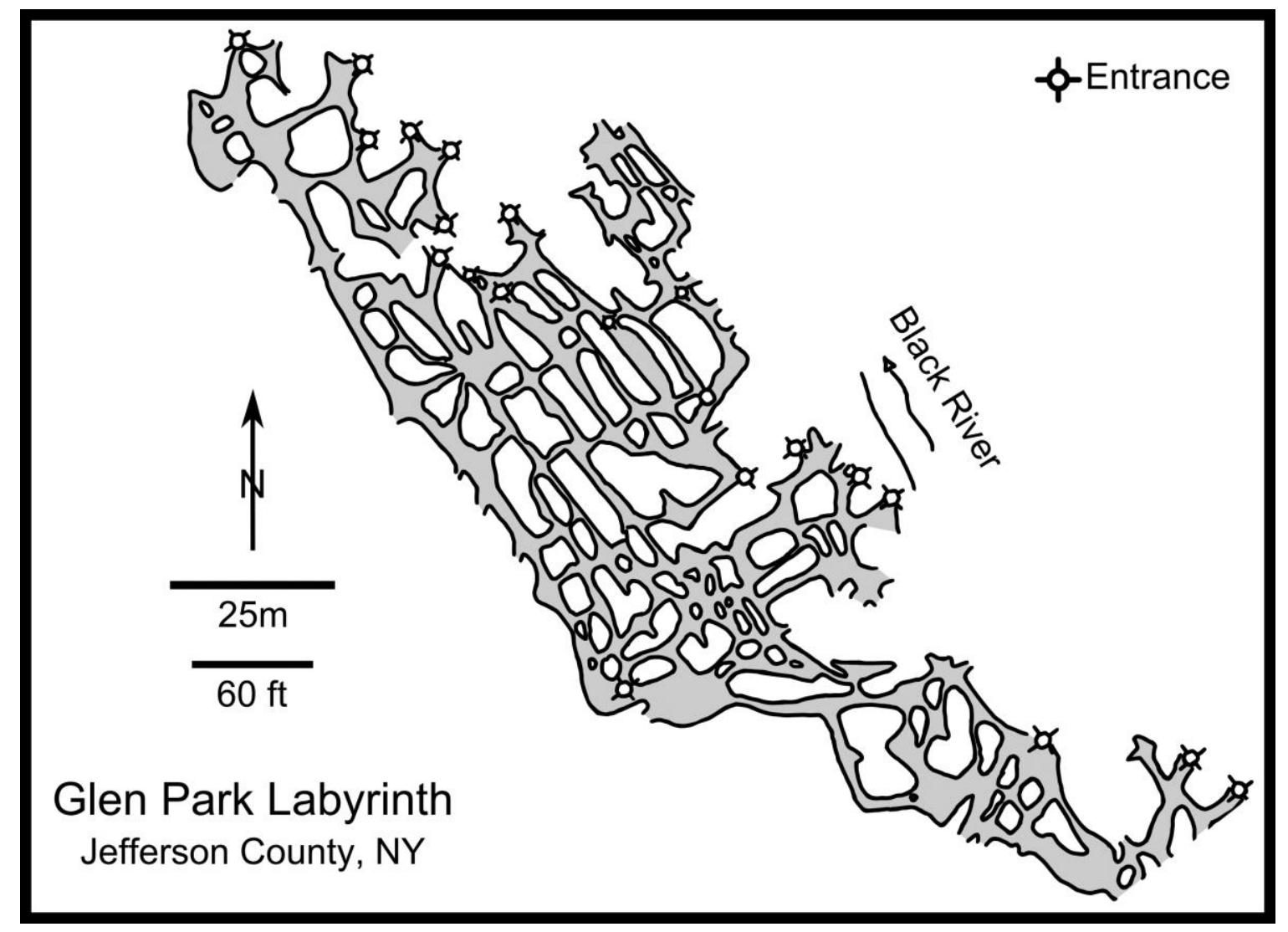

Cooper and Mylroie, 2015

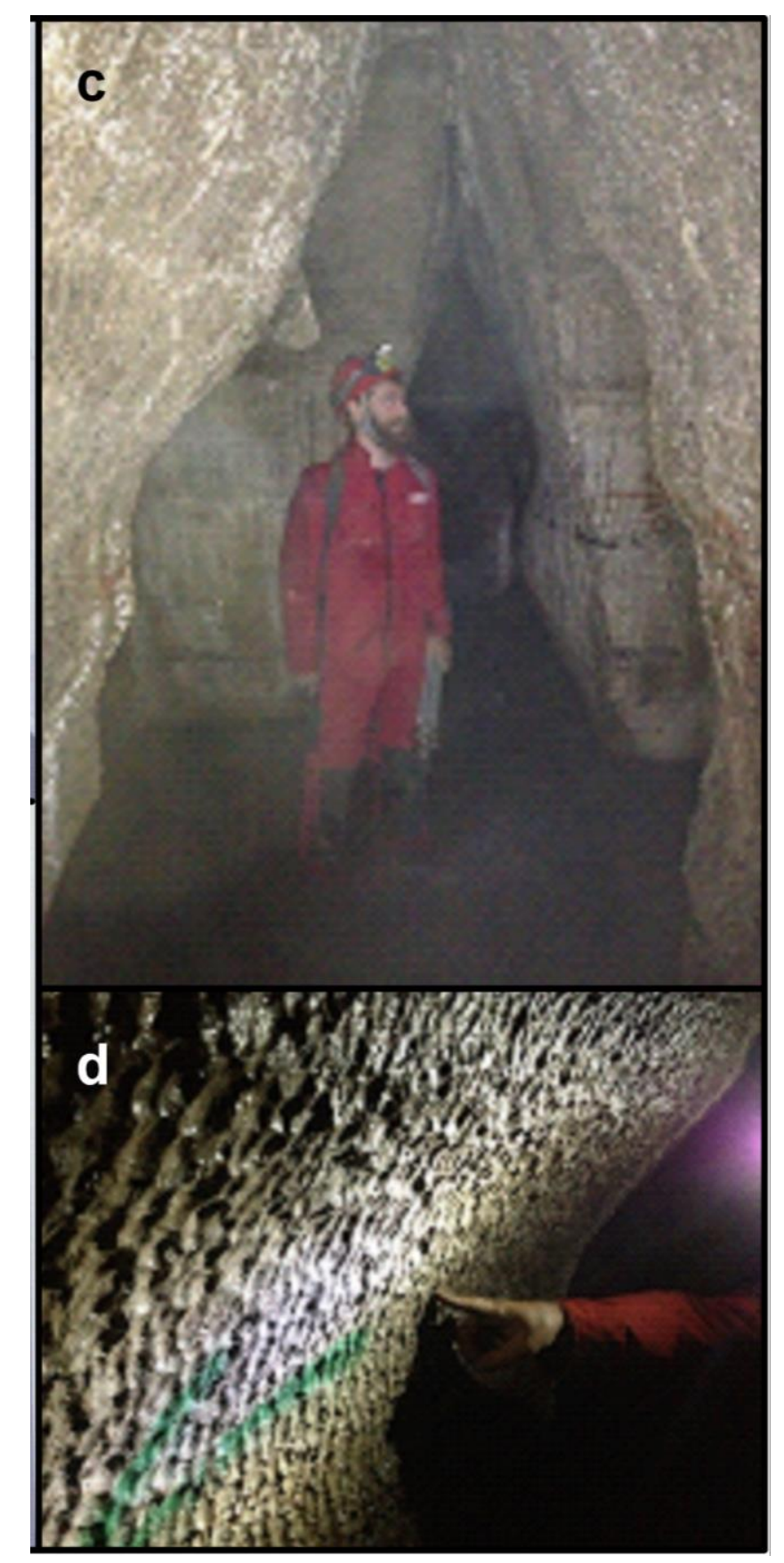


Cave systems show pre-glacial trunk passages with post-glacial infeeders

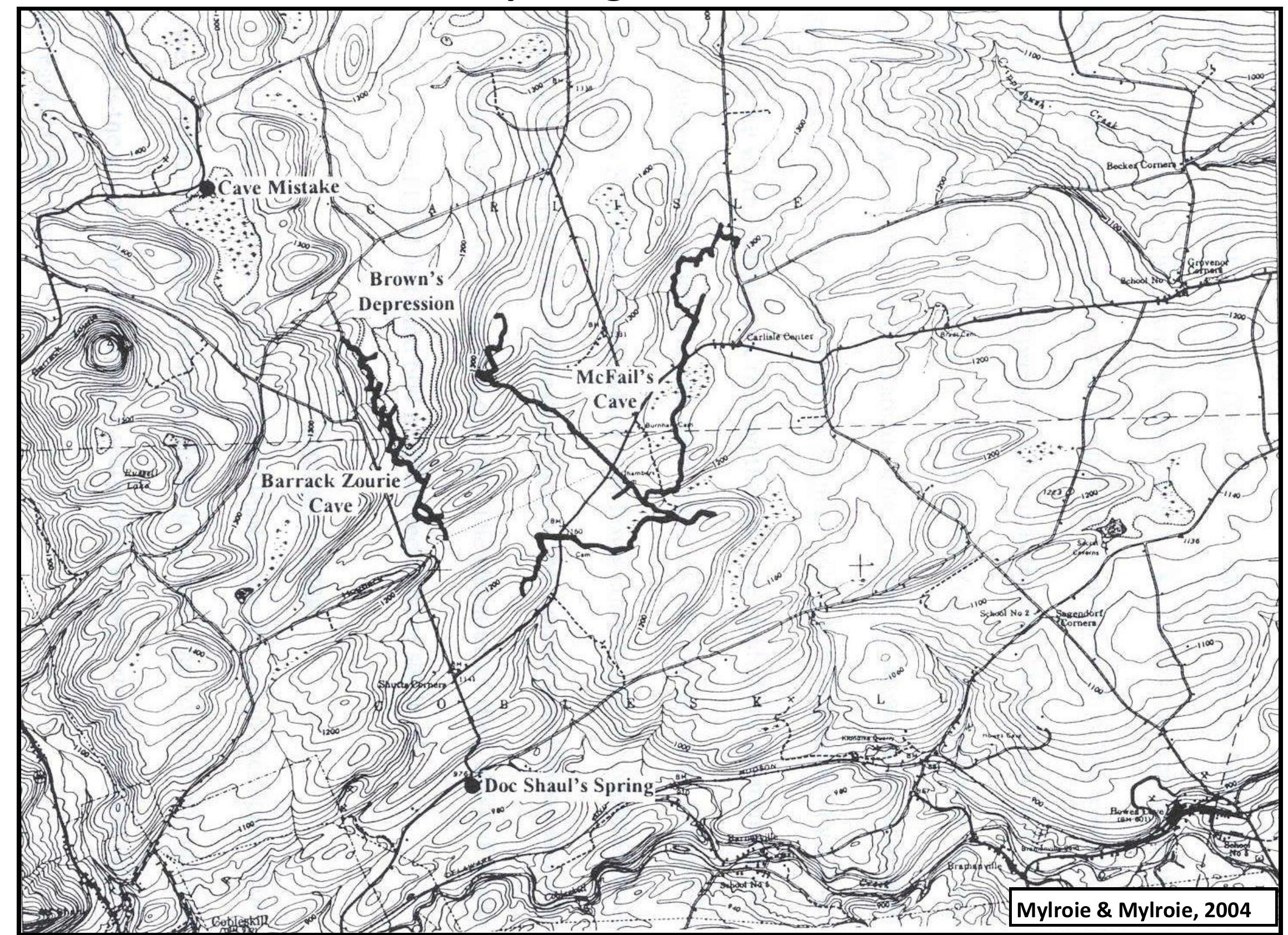


Doc Shauls Spring, the resurgence for McFails Cave, has piped upward $30 \mathrm{~m}$ through glacial till

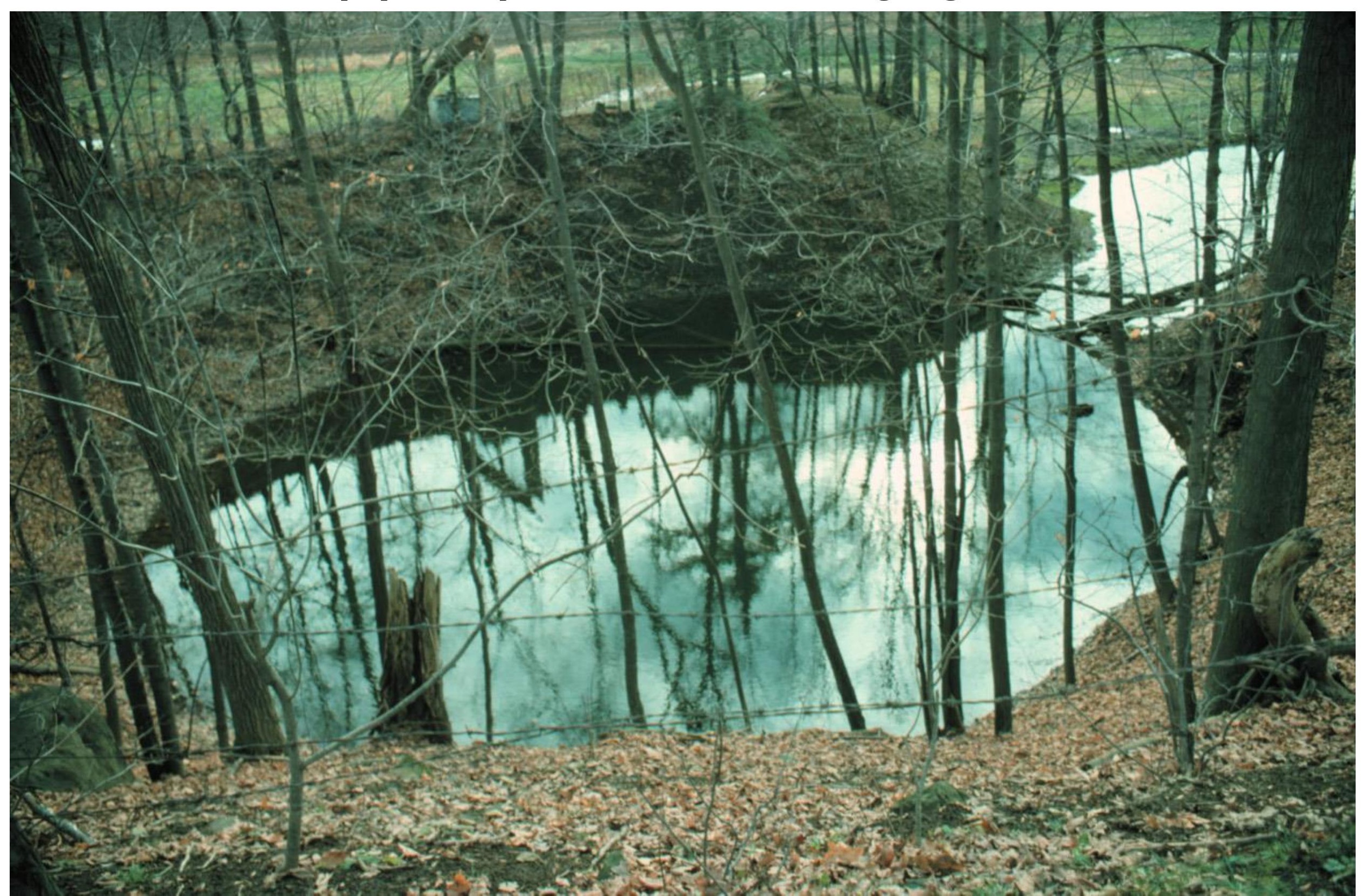


If inputs are new, what happens to outputs?

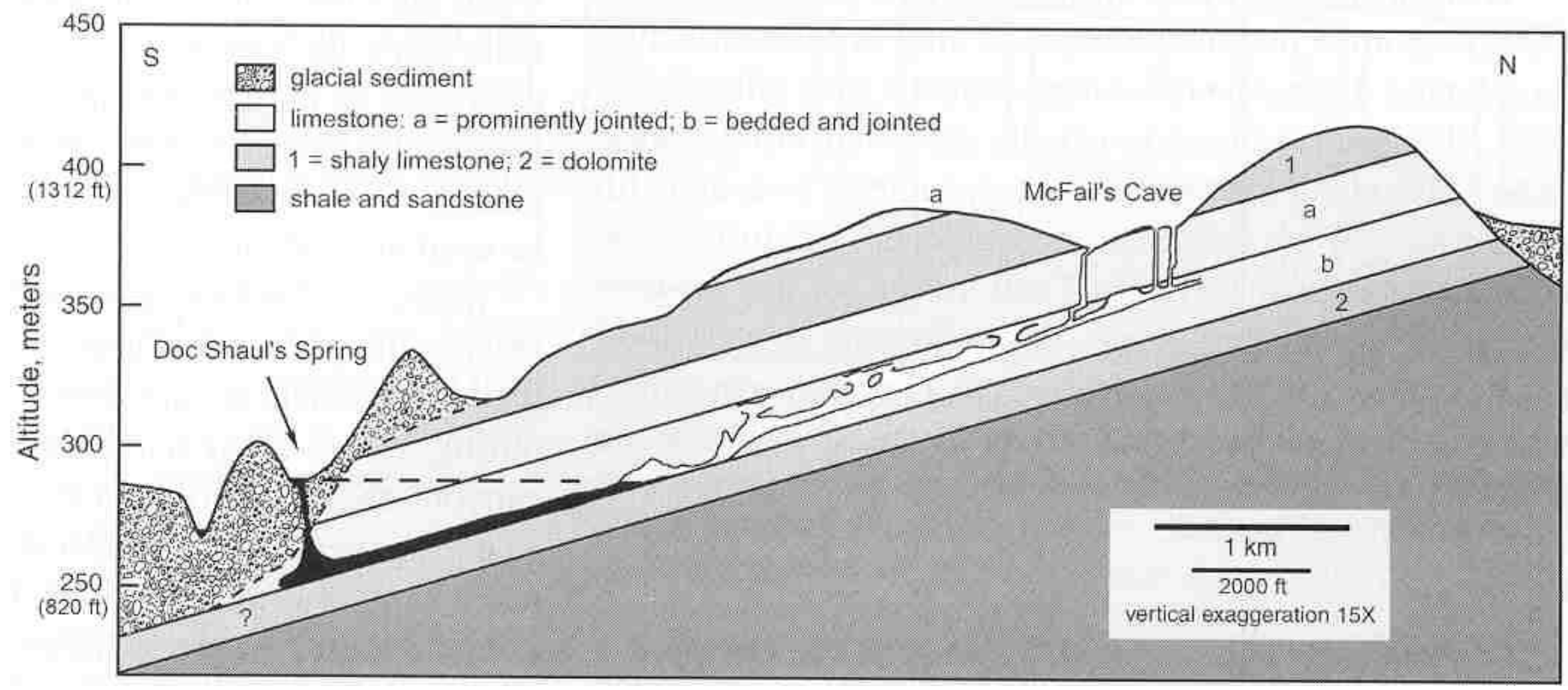

A. Palmer, 2007 


\section{Backflooding creates new passages}

\section{superimposed on pre-existing passages}

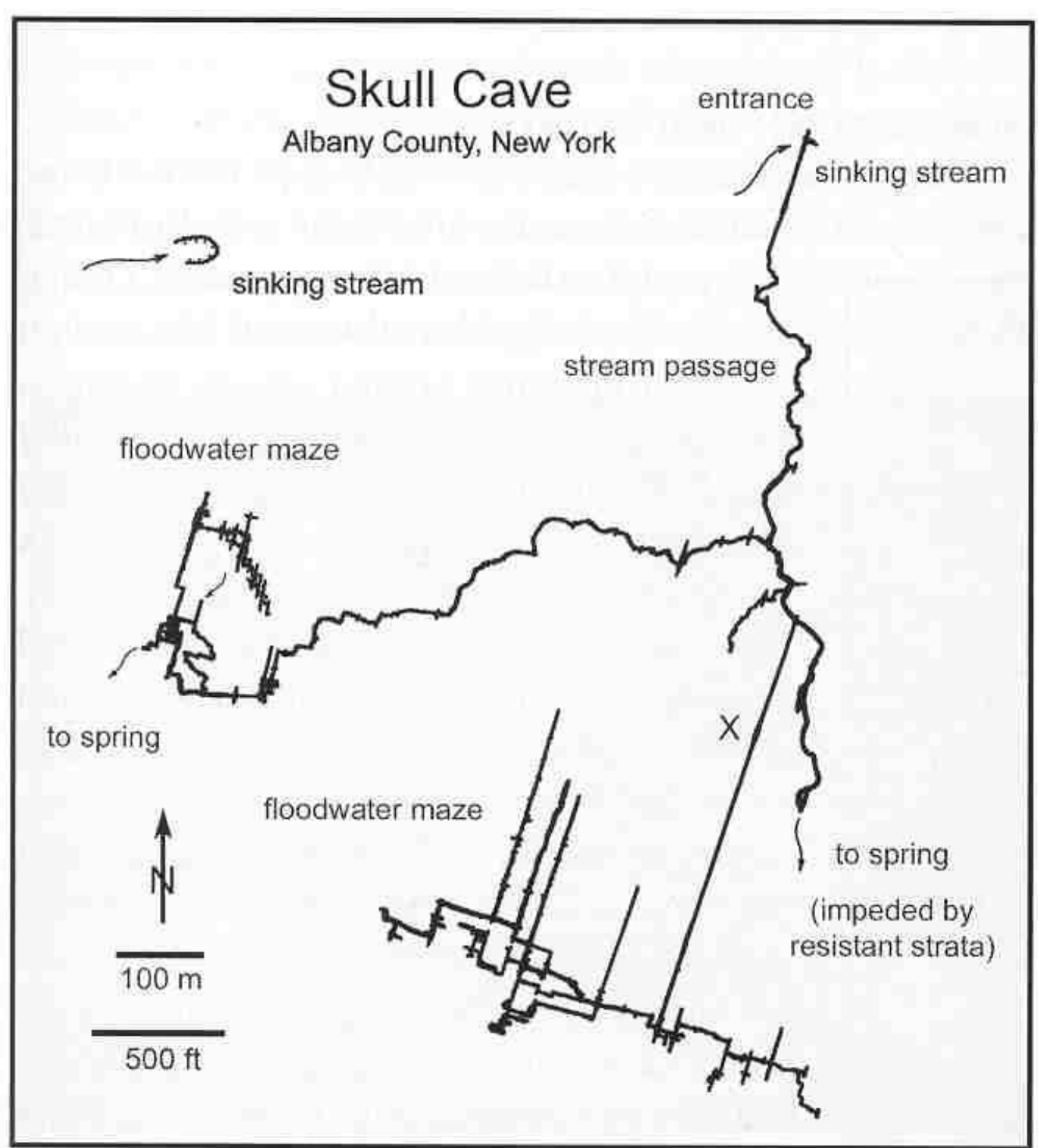

A. Palmer, 2007 


\section{Skull Cave, Albany County, NY}

Phreatic tube along strike Backflood joint passage

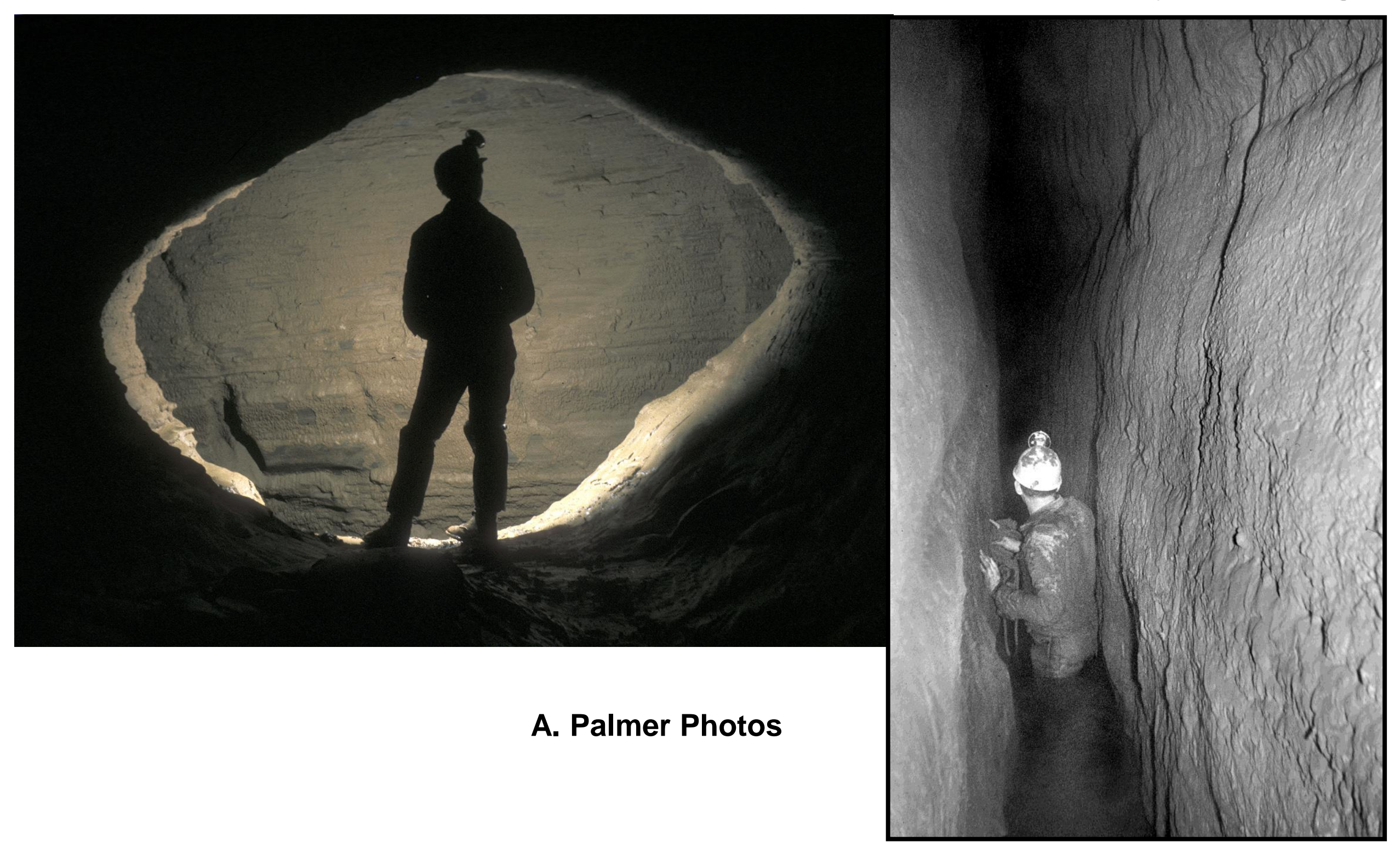


The key to resolving the question is to determine if caves are:

1. Persistent in the rock record......................YES

2. React rapidly to changing conditions...........YES

3. Survive those changing conditions..............YES

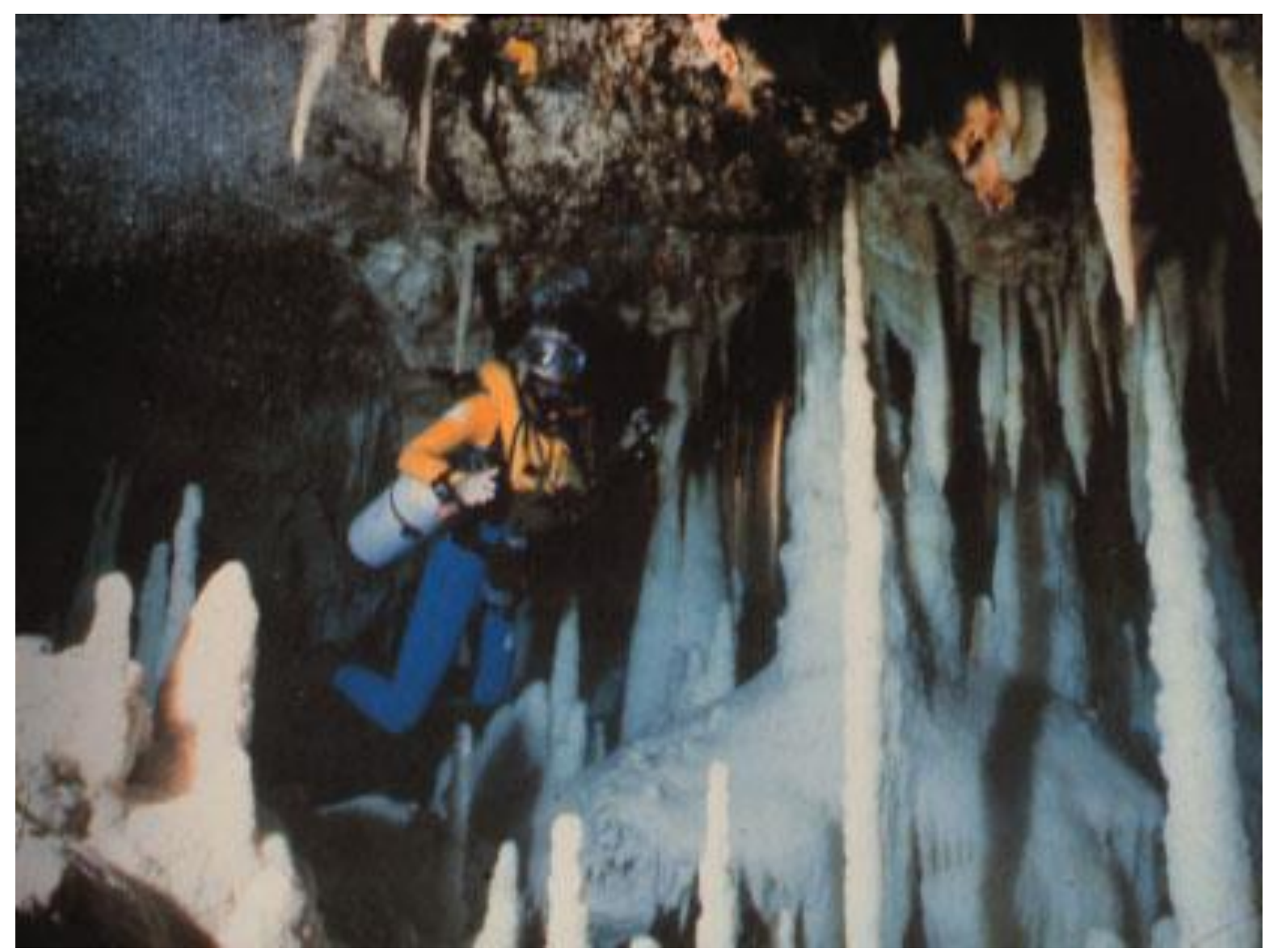

R. Palmer Photo,

Grand Bahama Island 
So, we ponder the question: Does glaciation matter?

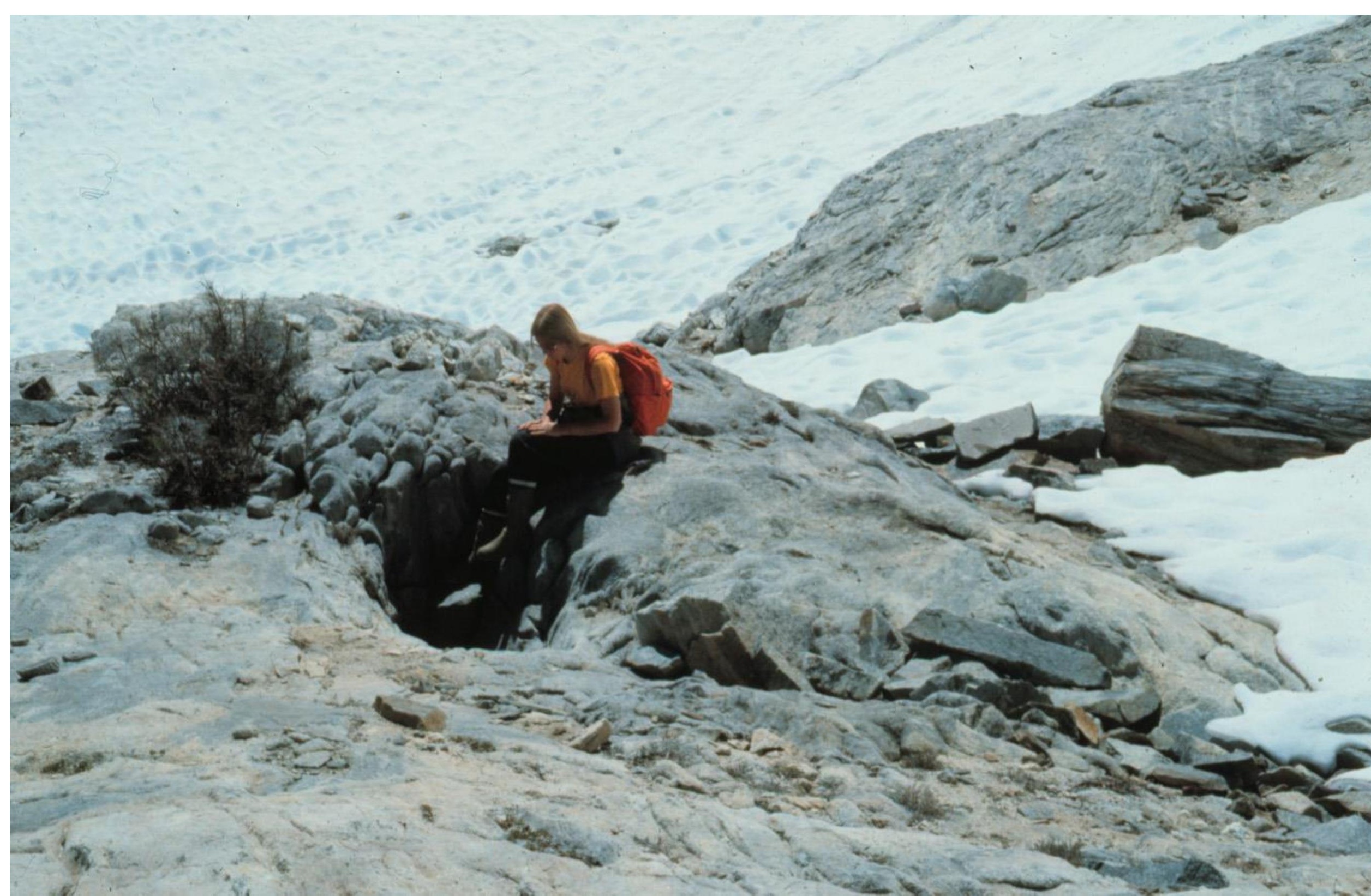




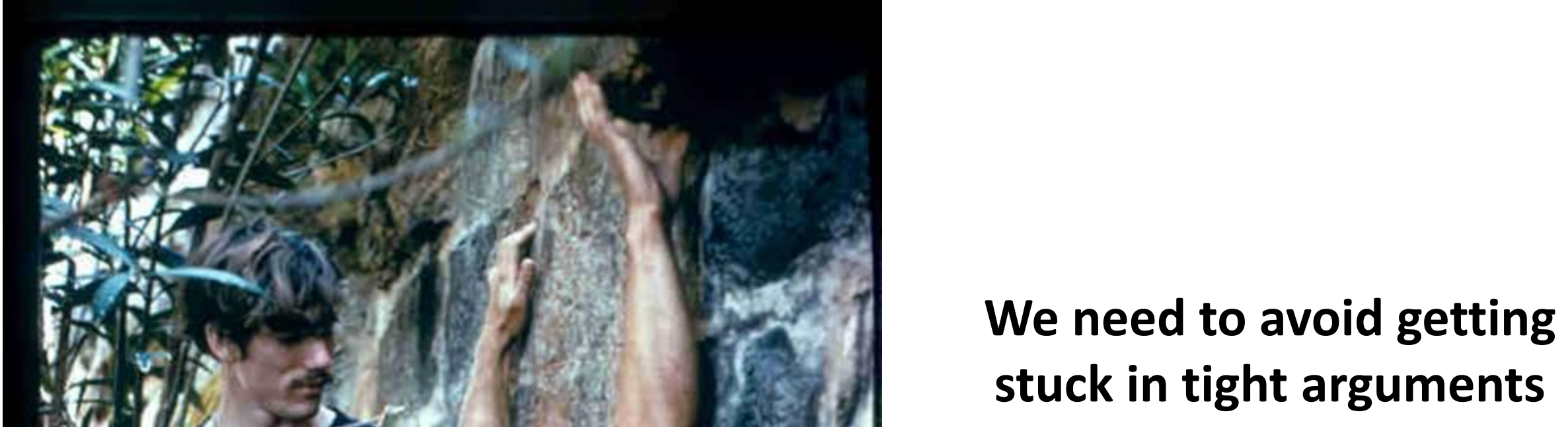

A. Palmer photo, Bermuda 


\section{CONCLUSION}

Do we cling to ideas of uniformitarianism, or do we recognize that epigenic cave and karst processes are a long-lived, high-fidelity record of all aspects of the variation in the Earth's surficial history? 


\section{THE END}

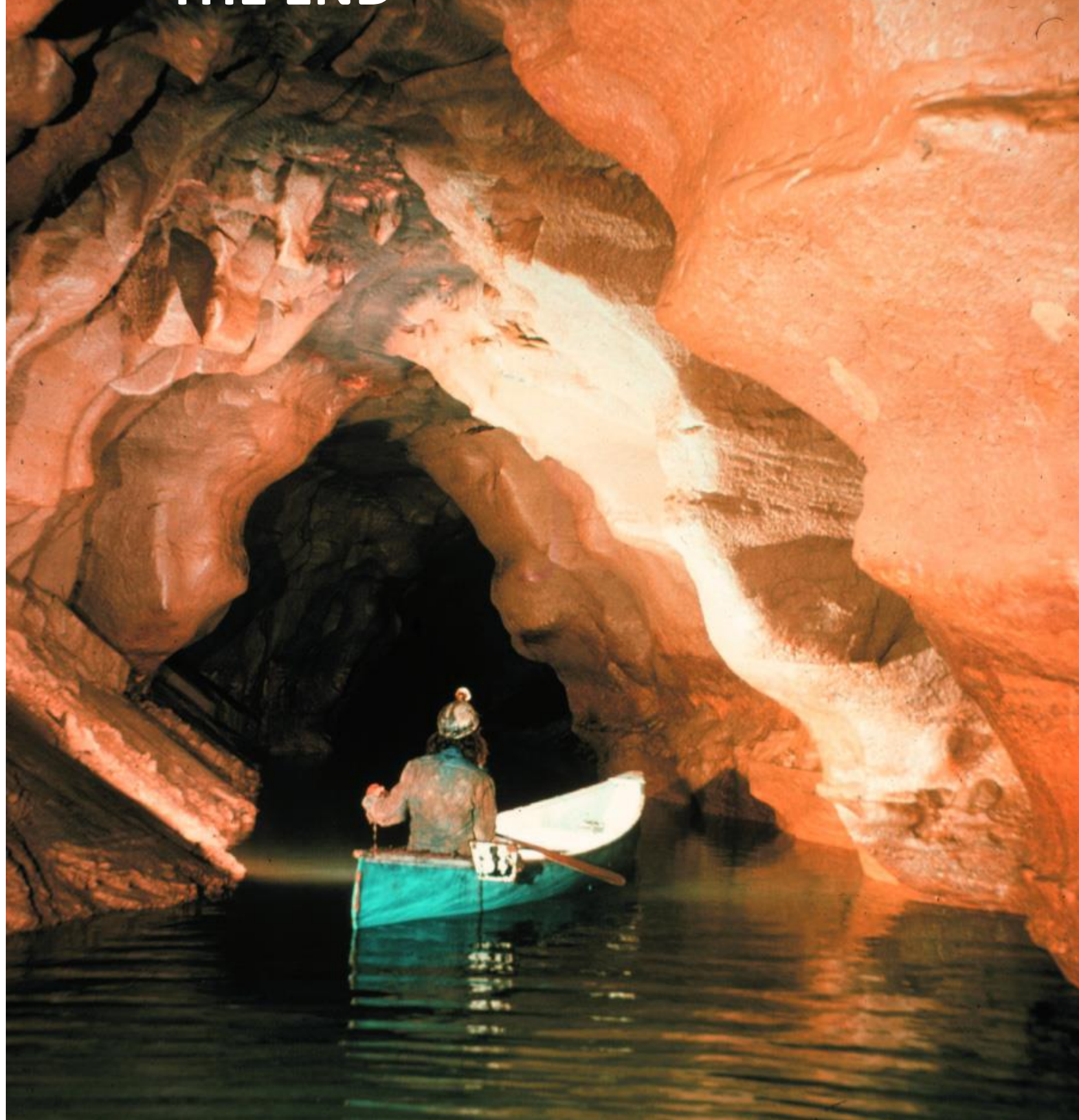

A. Palmer

photo,

Indiana 


\section{QUESTIONS?}

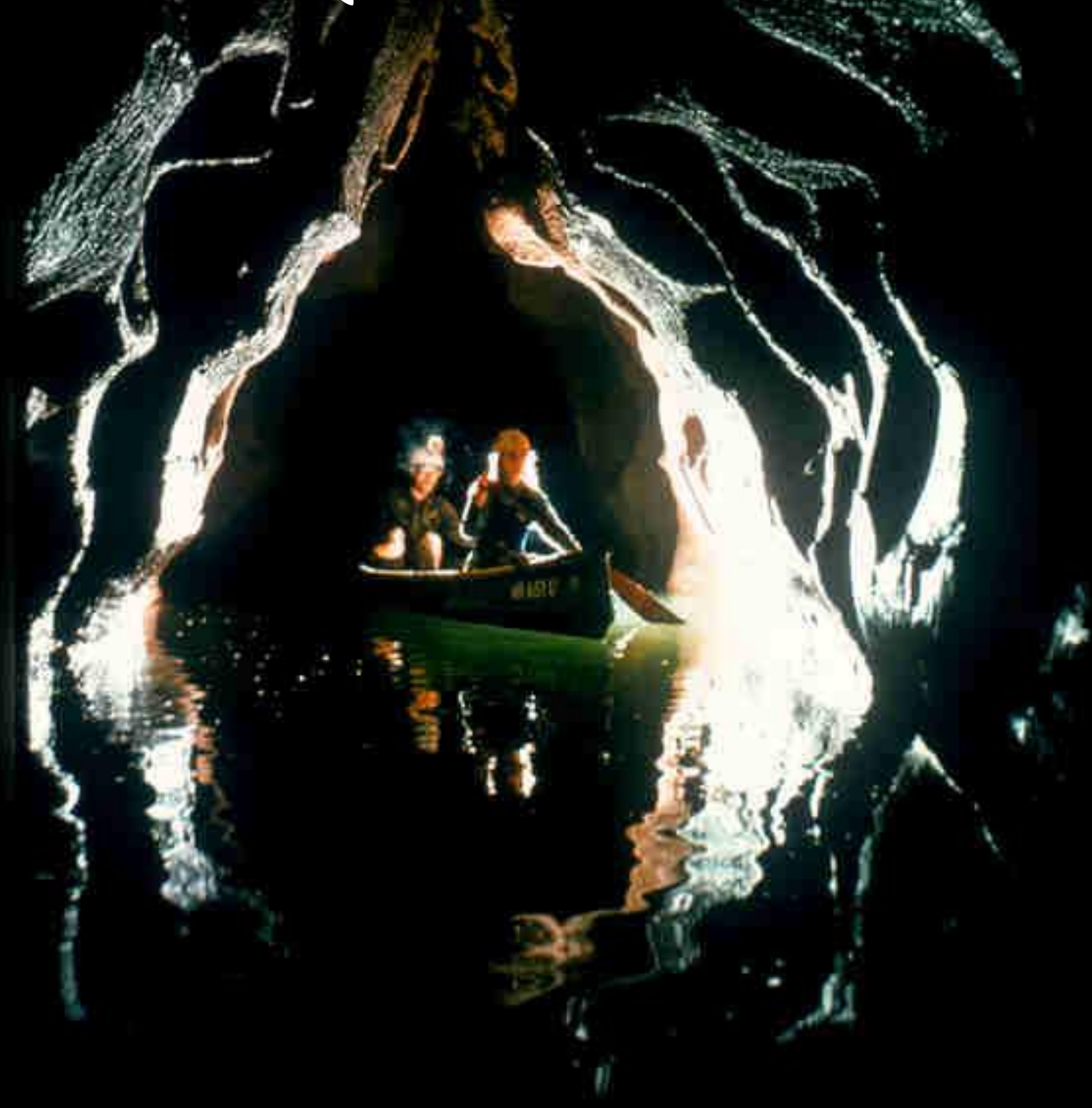

A. Palmer photo, Indiana 